\title{
Global atmospheric carbon budget: results from an ensemble of atmospheric $\mathrm{CO}_{2}$ inversions
}

\author{
P. Peylin ${ }^{1}$, R. M. Law ${ }^{2}$, K. R. Gurney ${ }^{3}$, F. Chevallier ${ }^{1}$, A. R. Jacobson ${ }^{4}$, T. Maki ${ }^{5}$, Y. Niwa ${ }^{5}$, P. K. Patra ${ }^{6}$, W. Peters ${ }^{7}$, \\ P. J. Rayner ${ }^{1,8}$, C. Rödenbeck ${ }^{9}$, I. T. van der Laan-Luijkx ${ }^{7}$, and X. Zhang ${ }^{3}$ \\ ${ }^{1}$ Laboratoire des Sciences du Climat et de l'Environnement, UMR8212, Gif sur Yvette, France \\ ${ }^{2}$ Centre for Australian Weather and Climate Research, CSIRO Marine and Atmospheric Research, Aspendale, Australia \\ ${ }^{3}$ School of Life Sciences/Global Institute of Sustainability, Arizona State University, Tempe, USA \\ ${ }^{4}$ University of Colorado Boulder and NOAA Earth System Research Laboratory, Boulder, Colorado, USA \\ ${ }^{5}$ Meteorological Research Institute, Tsukuba, Japan \\ ${ }^{6}$ Research Institute for Global Change, JAMSTEC, Yokohama, Japan \\ ${ }^{7}$ Dept. of Meteorology and Air Quality, Wageningen University, Wageningen, the Netherlands \\ ${ }^{8}$ School of Earth Sciences, University of Melbourne, Parkville, Australia \\ ${ }^{9}$ Max-Planck-Institute for Biogeochemistry, Jena, Germany \\ Correspondence to: P. Peylin (peylin@1sce.ipsl.fr)
}

Received: 30 January 2013 - Published in Biogeosciences Discuss.: 15 March 2013

Revised: 4 August 2013 - Accepted: 12 September 2013 - Published: 24 October 2013

\begin{abstract}
Atmospheric $\mathrm{CO}_{2}$ inversions estimate surface carbon fluxes from an optimal fit to atmospheric $\mathrm{CO}_{2}$ measurements, usually including prior constraints on the flux estimates. Eleven sets of carbon flux estimates are compared, generated by different inversions systems that vary in their inversions methods, choice of atmospheric data, transport model and prior information. The inversions were run for at least $5 \mathrm{yr}$ in the period between 1990 and 2010. Mean fluxes for 2001-2004, seasonal cycles, interannual variability and trends are compared for the tropics and northern and southern extra-tropics, and separately for land and ocean. Some continental/basin-scale subdivisions are also considered where the atmospheric network is denser. Four-year mean fluxes are reasonably consistent across inversions at global/latitudinal scale, with a large total (land plus ocean) carbon uptake in the north $\left(-3.4 \mathrm{Pg} \mathrm{C} \mathrm{yr}^{-1}\left( \pm 0.5 \mathrm{Pg} \mathrm{C} \mathrm{yr}^{-1}\right.\right.$ standard deviation), with slightly more uptake over land than over ocean), a significant although more variable source over the tropics $\left(1.6 \pm 0.9 \mathrm{Pg} \mathrm{C} \mathrm{yr}^{-1}\right)$ and a compensatory sink of similar magnitude in the south $\left(-1.4 \pm 0.5 \mathrm{Pg} \mathrm{C} \mathrm{yr}^{-1}\right)$ corresponding mainly to an ocean sink. Largest differences across inversions occur in the balance between tropical land sources and southern land sinks. Interannual variability (IAV) in carbon fluxes is larger for land than ocean regions (standard de-
\end{abstract}

viation around 1.06 versus $0.33 \mathrm{Pg} \mathrm{C} \mathrm{yr}^{-1}$ for the 1996-2007 period), with much higher consistency among the inversions for the land. While the tropical land explains most of the IAV (standard deviation $\sim 0.65 \mathrm{Pg} \mathrm{C} \mathrm{yr}^{-1}$ ), the northern and southern land also contribute (standard deviation $\left.\sim 0.39 \mathrm{Pg}_{\mathrm{yr}}^{-1}\right)$. Most inversions tend to indicate an increase of the northern land carbon uptake from late 1990s to 2008 (around $0.1 \mathrm{Pg} \mathrm{Cyr}^{-1}$ ), predominantly in North Asia. The mean seasonal cycle appears to be well constrained by the atmospheric data over the northern land (at the continental scale), but still highly dependent on the prior flux seasonality over the ocean. Finally we provide recommendations to interpret the regional fluxes, along with the uncertainty estimates.

\section{Introduction: context and objectives}

Atmospheric $\mathrm{CO}_{2}$ inversions offer a method by which to estimate carbon exchange between the land/ocean and atmosphere by utilizing atmospheric $\mathrm{CO}_{2}$ measurements, a key observational component of the global carbon cycle (e.g. their observed temporal and spatial gradients). Atmospheric $\mathrm{CO}_{2}$ inversions have a relatively long history with 
the first comprehensive efforts dating to the 1980s (Enting and Mansbridge, 1989; Tans et al., 1989). After over a decade of work by individual investigators, an intercomparison was attempted in the late 1990s (Gurney et al., 2002). This was driven, largely, by the fact that many of the individual atmospheric $\mathrm{CO}_{2}$ inversion efforts were arriving at distinctly different estimates of the land carbon sink (referred to initially as the residual or "missing" sink, deduced from fossil fuel emission, atmospheric accumulation, and ocean uptake) and it was sensible to attempt an improved understanding of the uncertainties and biases inherent to the problem.

This intercomparison effort, called "Transcom", included a number of experiments and sub-projects. Transcom remains a convenient title for a large community of inverse modelers who regularly gather, compare results, and perform various types of intercomparisons (e.g. Law et al., 1996; Denning et al., 1999; Gurney et al., 2002, 2004; Baker et al., 2006; Law et al., 2008; Patra et al., 2011). The major Transcom inversion intercomparison used a common inversion method across different transport models (Gurney et al., 2002, 2003), based on a Bayesian synthesis inversion method with a spatial discretization of 11 land and 11 ocean regions (Rayner et al., 1999). Annual mean, seasonal cycle, and interannual variability of the flux were analysed at different stages during the project (Gurney et al., 2002, 2003, 2004; Baker et al., 2006) along with a number of sensitivity studies (Engelen et al., 2002; Law et al., 2003; Maksyutov et al., 2003; Patra et al., 2003; Yuen et al., 2005; Patra et al., 2006; Gurney et al., 2008). In the early 2000s, new inversion approaches emerged, with different choices for spatial/temporal flux resolution, prior information, and observational constraints (Rödenbeck et al., 2003; Peters et al., 2005; Peylin et al., 2005; Chevallier et al., 2005, Maki et al., 2010). However, no exhaustive intercomparison has been performed between these recent estimates (i.e. from global to regional scales), apart from regional initiatives in Europe (Schulze et al., 2010) and North America (Hayes et al., 2012) and individual studies investigating only specific aspects of the carbon balance (e.g., Ciais et al., 2010, for the Northern Hemisphere long-term mean fluxes).

In this context, the results presented here are the latest comprehensive intercomparison. This effort was launched with the RECCAP initiative (REgional Carbon Cycle Assessment and Processes, Canadell et al., 2011) as part of the international Global Carbon Project (http://www.globalcarbonproject.org/reccap/). In this context, the objectives of the paper can be defined as follows:

- Gather $\mathrm{CO}_{2}$ flux estimates from recent atmospheric inversions and describe the main methodological similarities and differences between the selected systems.

- Compare the estimated posterior fluxes from the selected inversions using common processing.
- Analyze the fluxes in terms of long-term mean, longterm trend, interannual variations and mean seasonal variations and synthesize the most robust features at varying spatial scales.

- Provide guidelines and recommendations for using the inversion fluxes at the scale used in the RECCAP regional studies.

The paper is divided into four main sections. In Sect. 2, inverse modelling principles and general issues related to the problem of inverting $\mathrm{CO}_{2}$ fluxes over the globe are provided. Section 3 reviews the main characteristics of the selected set of inversions. In Sect. 4, the global to continental-scale flux estimates are compared and analyzed at different temporal scales. Finally, the last section discusses issues involved with interpreting inversion results at regional scale.

\section{Inversion methodology}

\subsection{Principles of atmospheric inversion}

Atmospheric $\mathrm{CO}_{2}$ inversions estimate surface-to-atmosphere carbon fluxes using atmospheric $\mathrm{CO}_{2}$ concentration measurements (see for instance Enting, 2002). The objective is to use the information from the temporal and spatial $\mathrm{CO}_{2}$ gradients to constrain a priori estimates of the net carbon exchange at the earth surface, including the anthropogenic component that is prescribed in the system. The prior natural fluxes are usually derived from a terrestrial/ocean dynamical model that can range from a complex process-based model to a simple linear model as in Rödenbeck (2005). The link between the surface fluxes to be optimized (or model state, $\mathbf{x}$ ) and the observations is made through the use of an observational operator, namely an atmospheric transport model $(H)$ :

$\boldsymbol{y}=H(\boldsymbol{x})+\boldsymbol{r}$,

where $\boldsymbol{y}$ is a vector of the model-predicted observed variables (atmospheric $\mathrm{CO}_{2}$ ), and $\boldsymbol{r}$ represents errors associated with measurements, representativeness (i.e. scale differences between model and observed concentrations), and the transport model (Kaminski et al., 2001).

The separation of the problem into observational and prior-knowledge components allows one to explicitly minimize the difference between the simulated and observed quantities (i.e. atmospheric concentration) in addition to minimizing the difference between the optimized fluxes and "background" or "reference" values (i.e. a priori surface fluxes). This can be recast in Bayesian terms as the maximization of the probability density function (PDF) of the state variables given observations. Assuming Gaussian error distributions, the maximum of the PDF corresponds to the 
minimum of the objective function, $J^{1}$,

$$
\begin{aligned}
J(\boldsymbol{x})= & \left(\boldsymbol{x}-\boldsymbol{x}_{b}\right)^{T} \mathbf{B}^{-1}\left(\boldsymbol{x}-\boldsymbol{x}_{b}\right)+\left(\boldsymbol{y}_{\mathrm{obs}}-H(\boldsymbol{x})\right)^{T} \mathbf{R}^{-1} \\
& \left(\boldsymbol{y}_{\mathrm{obs}}-H(\boldsymbol{x})\right),
\end{aligned}
$$

where $\mathbf{B}$ is the covariance matrix for the background or reference state variables and $\mathbf{R}$ is the covariance matrix for the observations. These covariance matrices can be interpreted as weighting functions determining the extent to which the solution is influenced by the atmospheric data versus prior knowledge.

Note that this process can also be thought of as a particular application of a more general problem, described variously as model-data fusion, parameter estimation or data assimilation (DA) (Evans and Stark, 2002; Tarantola, 2005; Raupach et al., 2005). Indeed, the theoretical underpinnings of the atmospheric inverse approach have seen wide application in many branches of geophysics, economics, and systems engineering, to name a few. Recently, new atmospheric inverse approaches have emerged with the objective of constraining directly the parameters of a terrestrial/ocean dynamical model; they are usually referred as Carbon Cycle Data Assimilation Systems (CCDAS, Rayner et al., 2005).

\subsection{Inversion methods: practical implementation}

\subsubsection{Optimization method}

A variety of approaches can be employed in finding the values of $\mathbf{x}$ that minimize the above-mentioned objective function (Tarantola, 1987; Rodgers, 2000; Enting, 2002). Sequential approaches, in which the optimization occurs at regular intervals in time, can be used with different classes of the Kalman filter (Kalman, 1960; Evensen, 2007). An alternative is to simultaneously fit all the observations in the study period, either using a variational scheme such as in operational weather forecasting (Courtier et al., 1994) or an analytical scheme (Tarantola, 1987) when the dimensions of the problem are small enough to allow storage of the matrix in computer memory (and their algebraic inversion). If the model $H$ is a linear operator $\mathbf{H}$, the posterior information on $\mathbf{x}$ follows a Gaussian PDF with mean value $\mathbf{x}_{\mathbf{a}}$, and error covariance matrix $\mathbf{A}$ that can be calculated at least with two equivalent expressions $^{2}$ :

$$
\begin{aligned}
& \mathbf{x}_{\mathbf{a}}=\mathbf{x}_{\mathbf{b}}-\mathbf{A H}^{\mathbf{T}} \mathbf{R}^{-\mathbf{1}}\left(\mathbf{H} \mathbf{x}^{\mathbf{b}}-\mathbf{y}\right)=\mathbf{x}_{\mathbf{b}}-\mathbf{B} \mathbf{H}^{\mathbf{T}} \\
& \left(\mathbf{H B H} \mathbf{H}^{\mathbf{T}}+\mathbf{R}\right)^{-\mathbf{1}}\left(\mathbf{H x}_{\mathbf{b}}-\mathbf{y}\right)
\end{aligned}
$$

$$
\mathbf{A}=\left(\mathbf{H}^{\mathrm{T}} \mathbf{R}^{-\mathbf{1}} \mathbf{H}+\mathbf{B}^{-\mathbf{1}}\right)^{-\mathbf{1}}=\mathbf{B}-\mathbf{B} \mathbf{H}^{\mathrm{T}}\left(\mathbf{H B} \mathbf{H}^{\mathrm{T}}+\mathbf{R}\right)^{-\mathbf{1}} \mathbf{H B}
$$

Alternatively, in the variational approach, $\mathbf{x}_{\mathbf{a}}$, the minimum of $J$ can be estimated through an iterative descent algorithm,

\footnotetext{
${ }^{1}$ Notation follows the convention defined by Ide et al. (1997).

${ }^{2}$ The two expressions rely on different sizes of the matrix to invert.
}

using the gradient of $J(\nabla J)$ at each iteration. Such computation usually employs the adjoint technique in the case of large problems (Errico, 1997) and implies that $\mathbf{R}$ and $\mathbf{B}$ can be inverted (either being diagonal or having specific properties). In this approach the estimation of $\mathbf{A}$ (corresponding to the inverse of the Hessian of $J$ ) becomes more difficult and only selected elements corresponding to target quantities (e.g., regional averages) are usually estimated (Rödenbeck, 2005; Chevallier et al., 2010).

The choice of a particular formulation is usually guided by practical considerations: analytical approaches can be used if the number of observations or unknown variables is less than a few thousands and if all $\mathbf{H}$ terms can be calculated, while a variational approach is used for problems with larger size. Note that variational/analytical methods have the advantage of all state variables being exposed to all observations at once, while specific algorithms of the Kalman filter may have the advantage of smaller computational demand.

In this study, we present a number of atmospheric $\mathrm{CO}_{2}$ inversions that employ this general approach, with differences in the detailed specification, which will be given in the inversion description (Sect. 3).

\subsubsection{Atmospheric $\mathrm{CO}_{2}$ observations}

Atmospheric surface $\mathrm{CO}_{2}$ observations are obtained from a global network of more than 100 sites where $\mathrm{CO}_{2}$ is measured either continuously ( $\sim 50$ sites), or via discrete flask air samples (weekly; $\sim 100$ sites). The current network is part of an international effort that started $55 \mathrm{yr}$ ago with a continuously growing number of sites. Most of the sites are currently incorporated into the GLOBALVIEW data product (GLOBALVIEW-CO2: Cooperative Atmospheric Data Integration Project - Carbon Dioxide. NOAA ESRL, Boulder, Colorado (available at http://www.esrl.noaa.gov/gmd/ccgg/ globalview/)) and are also available through the World Data Center for Greenhouse Gases (WDCGG). However, even with current networks, the interiors of most continents, as well as key areas of the ocean (i.e. southern oceans), remain undersampled with only a few space stations. Until recently, most inversions used data primarily from remote stations with air masses representing large-scale sources and sinks; coastal or inland station records would be selected, e.g. by wind sector or time of day, to avoid the influence of local fluxes. For flask samples, this selection occurs by choosing the sampling time, often with removal of outliers when the data are processed. More recently, inversion studies making use of improvements in modelled atmospheric transport are making greater use of continuous records of atmospheric $\mathrm{CO}_{2}$. For continental sites, these are usually selected by time of day when transport models are expected to perform better (e.g., well-mixed conditions around local noon). Finally, note that none of the inversions considered in this study use column-integrated $\mathrm{CO}_{2}$ observations acquired from space (as was done by Chevallier et al., 2011). Further, though the 
growing number of vertical $\mathrm{CO}_{2}$ profiles (not yet assimilated in the selected inversions) would be useful to independently check on the inverse results (Stephens et al., 2007), exploiting them is a task beyond the scope of this paper.

\subsubsection{Prior information}

As noted previously, prior fluxes (or flux covariations) and prior flux uncertainties are utilized to supplement the primary constraint supplied by the observed $\mathrm{CO}_{2}$ concentrations. Prior fluxes are used to maintain a rational posterior result where $\mathrm{CO}_{2}$ observations are insufficient to constrain the degrees of freedom endemic to the inversion setup. The use of prior fluxes, their space/time distribution and numerical magnitude has engendered much discussion and debate. It is worth noting that prior fluxes cannot be discussed separately from the prior flux uncertainties, as the latter determines to what extent the priors are relied upon to constrain the posterior flux estimates.

Different inversion system groups have chosen different prior fluxes and uncertainties. The general approach is to utilize prior fluxes that are based on either independent model or observed estimates, such as net carbon exchanges as estimated by terrestrial or oceanic biogeochemical models (TBM, OBM). Most TBMs rely on different process formulations and to varying degrees upon observations or observed drivers (e.g. radiation, temperature, precipitation) but the quality of estimates varies depending upon the region considered (Sitch et al., 2008) and this reveals the extent to which net carbon exchange remains a challenging quantity to model.

The anthropogenic $\mathrm{CO}_{2}$ source to the atmosphere due to the combustion of fossil fuel (coal, gas, oil, cement production) is the main perturbation to the carbon cycle. It is known within 5-10\% from energy statistics (Andres et al., 2011, 2012) at the global scale, but with large uncertainties on the space/time distribution, particularly in industrial regions. Geographic patterns of fossil fuel $\mathrm{CO}_{2}$ sources are needed as an a priori ingredient in the inverse problem, due to their high spatial heterogeneity. Although uncertainties in those emissions may substantially impact the annual land flux estimates at the regional scale (Gurney et al., 2005; Peylin et al., 2011), most inversions prescribe fossil fuel $\mathrm{CO}_{2}$ fluxes and do not account explicitly for their uncertainty. This is discussed in more detail in Sect. 3.3.

\section{Participating inversion systems}

\subsection{Selected inversions}

The LSCE Laboratory has been collecting carbon flux estimates from state-of-the-art inversions performed by groups around the world in an effort to construct a new atmospheric $\mathrm{CO}_{2}$ inversion intercomparison. Since the Transcom 3 inversion intercomparison of the early 2000s (Gurney et al., 2002,
2004; Baker et al., 2006), little effort has been made to systematically compare and synthesize the results of more recent inversions.

Within the Transcom community, LSCE proposed sharing inversion results. Unlike the earlier Transcom 3 inversion intercomparison, there are no prescribed priors or a priori uncertainties, no prescribed inverse method and no prescribed observational data set, such that the ensemble of runs encompasses a wide range of methodological choices by the individual inversion groups. The only technical requirement was to separately provide the estimated land and ocean fluxes and the fossil fuel emissions. The results of these inversions are currently displayed through a web-site (https://transcom.lsce.ipsl.fr to be migrated under http://webportals.ipsl.jussieu.fr/), and represent 14 different approaches.

For the purpose of satisfying the RECCAP goals, eleven of the submissions to LSCE were selected (Table 1). The criteria used for the RECCAP synthesis was that the inversion results must span a time period of at least $5 \mathrm{yr}$ (in order to examine interannual variations). However a specific $5 \mathrm{yr}$ period was not required. The specificities of the selected inversions and key associated references are briefly described in Supplement and summarised in Table 1. Note that inversion $\operatorname{TrC}$ is an ensemble mean of 13 inversions constructed using the inversion methodology of the Transcom 3 experiment (Gurney et al., 2002) and model submissions from that intercomparison. We consider this as a single submission so that the results across inversions would not be biased towards a large number of inversions using a single methodology.

Note that for the selected systems we took the most recent flux estimates (early 2013) and that for five systems (JENA, MACC-II, NICAM, CT2011_oi, and CTE2013) older estimates have been used in the other RECCAP synthesis papers (released in 2011). We provide at the end of the Supplement a section describing the main differences between the old and new versions of the five systems as well as key figures with the old submissions (Figs. S9 to S12).

\subsection{Main differences between the selected inversions}

The participating submissions reflect a range of choices for atmospheric observations, transport model, spatial and temporal flux resolution, prior fluxes, observation uncertainty and prior error assignment, and inverse method. We summarize here the differences among the selected inversions and the likely impact on the estimated $\mathrm{CO}_{2}$ fluxes. Note that the updated inversions do not result in any significant changes to the analysis presented here; the most notable difference is a general tendency to reduced spread across inversion results.

\subsection{1 $\mathrm{CO}_{2}$ observing networks}

Previous work (Law et al., 2003; Patra et al., 2006; Gurney et al., 2008) has shown that the fluxes estimated in the 
Table 1. Participating inversion systems and key attributes.

\begin{tabular}{|c|c|c|c|c|c|c|c|}
\hline Acronym & Reference & \# of regions & Time Period & $\mathrm{Obs}^{1}$ & $\#$ of obs locations ${ }^{2}$ & $\mathrm{IAV}^{3}$ wind & IAV $^{4}$ priors \\
\hline LSCEa & Piao et al. (2009) & $\begin{array}{l}\text { Grid cell } \\
(96 \times 72)\end{array}$ & 1996-2004 & MM & 67 & Yes & No \\
\hline MACC-II & Chevallier et alal. (2010) & $\begin{array}{l}\text { Grid cell } \\
(96 \times 72)\end{array}$ & 1988-2011 & Raw & 134 & Yes & Yes \\
\hline CCAM & Rayner et al. (2008) & 146 & 1992-2008 & MM & $\begin{array}{c}73 \mathrm{CO}_{2} \\
7 \delta^{13} \mathrm{CO}_{2}\end{array}$ & No & No \\
\hline MATCH & Rayner et al. (2008) & 116 & 1992-2008 & MM & $\begin{array}{c}73 \mathrm{CO}_{2} \\
7 \delta^{13} \mathrm{CO}_{2}\end{array}$ & No & No \\
\hline CT2011_oi & Peters et al. (2007) & 156 & $2001-2010$ & Raw & 96 & Yes & Yes \\
\hline CTE2013 & Peters et al. (2010) & 168 & 2001-2010 & Raw & 117 & Yes & Yes \\
\hline $\begin{array}{l}\text { JENA } \\
\text { (s96, v3.5) }\end{array}$ & Rödenbeck (2005) & $\begin{array}{l}\text { Grid cell } \\
(72 \times 48)\end{array}$ & 1996-2011 & Raw & 50 & Yes & No \\
\hline $\begin{array}{l}\text { RIGC } \\
\text { (TDI-64) }\end{array}$ & Patra et al. (2005a) & 64 & 1989-2008 & MM & 74 & Yes & No \\
\hline JMA & Maki et al. (2010) & 22 & 1985-2009 & MM & 146 & Yes & No \\
\hline $\operatorname{TrC}$ & Gurney et al. (2008) & 22 & 1990-2008 & MM & 103 & No & No \\
\hline NICAM & Niwa et al. (2012) & 40 & 1988-2007 & MM & 71 & Yes & No \\
\hline
\end{tabular}

1 Observations used as monthly means (MM) or at sampling time (Raw).

${ }^{2}$ Number of measurement locations included in the inversion (some inversions use multiple records from a single location).

${ }^{3}$ Inversion accounts for interannually varying transport (Yes) or not (No).

${ }^{4}$ Inversion accounts for interannually varying prior fluxes (Yes) or not (No).

inverse approach can be very sensitive to the composition of the $\mathrm{CO}_{2}$ observing network used (Fig. 1). This is particularly true for parts of the world where there are few observing sites; it is directly reflected in the estimated flux uncertainties (see Table 2) with larger values. Interannual variations (IAV) in the inversely estimated fluxes can also be sensitive to particular observing sites and the overall network composition. Accurate quantification of the flux variability may be confounded by changes in the availability of observations through the estimation time period (Rödenbeck et al., 2003). Most inversions attempt to minimize this spurious variability by only using sites that are available for the full period of the inversion (LSCEa, JENA, RIGC), or by making use of the interpolated data in the GLOBALVIEW data product (CCAM, MATCH, TrC, NICAM). Note that the two CarbonTracker estimates (CT2011_oi, CTE2013) assimilate all data that were positively quality controlled by the inverse modelling team (i.e. removing outliers). The list of the observation sites and data selection criteria used in each of the participating inversion systems can be found in the Supplement. Overall, the number of sites varies by a factor of almost three, i.e. between 50 (JENA) and 146 (JMA) (Table 1). Some inversions directly assimilate raw data at the appropriate sampling time (weekly flasks or continuous record; MACC-II, CT2011_oi, CTE2013, JENA) while the other systems only use monthly mean values derived mainly from the GLOBALVIEW data product or from WDCGG (JMA). In general the GLOBALVIEW product uses data selected for clean-air conditions.
Finally, CCAM and MATCH additionally assimilate measurements of the ${ }^{13} \mathrm{C} /{ }^{12} \mathrm{C}$ isotopic ratio of $\mathrm{CO}_{2}$ to further constrain the partition between land and ocean carbon fluxes (Rayner et al., 2008). Note also that all groups have performed sensitivity tests with some stations added or left out. In this study we analyze only one variant of each inversion.

The inversion method requires an uncertainty to be assigned to each $\mathrm{CO}_{2}$ observation. This provides a relative weighting for each observation to determine the estimated fluxes. This uncertainty accounts for measurement errors as well as model errors (including representation error, i.e., the mismatch between the modelled spatial scale and the observed spatial scale). The model error is generally the largest contribution and it depends on each transport model's characteristics. In general, all inversions place smaller uncertainties on remote ocean sites than on continental sites (see Supplement for the error range of each system).

\subsubsection{Transport models}

The different inversions used different transport models (see Supplement), except that CT2011_oi and CTE2013 both use the TM5 model but zoomed over either the US or both the US and Europe; LSCEa and MACC-II use two successive versions of the LMDZ model. Most of the participants drive their transport algorithms with interannually varying winds (Table 1), except for CCAM, MATCH, and $\operatorname{TrC}$ that utilize a single year of winds, which is repeated to achieve multiyear results (a simplification that should be kept in mind when discussing the interannual flux variations). The value 


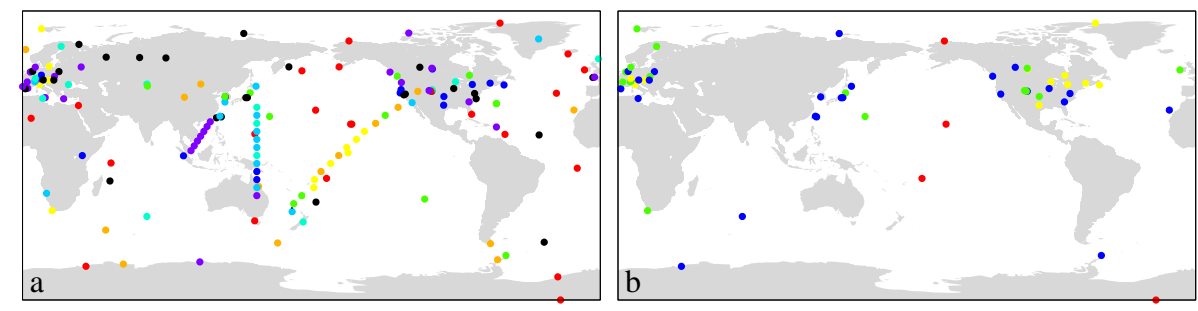

Fig. 1. Map of the site locations. Left shows all site locations used by any inversion with the color representing the number of inversions that use that site: black: 1 , purple: 2, dark blue: 3, light blue: 4, cyan: 5-6, green: 7-8, yellow: 9, orange: 10, red: 11; right: in situ sites that are used by up to 4 inversions at hourly or daily temporal resolution. Color indicates the number of inversions, 1 (blue), 2 (green), 3 (yellow), 4 (red).

of using interannually varying (IAV) transport was explored by Dargaville et al. (2000) and Rödenbeck et al. (2003), with the earlier study suggesting that utilizing IAV transport was less important than the later study.

\subsubsection{Flux resolution}

The number of adjustable degrees of freedom of the participating submissions varies considerably from the original 22 Transcom-3 land and ocean regions (JMA, TrC) to the transport model grid cells (LSCEa, MACC-II, JENA) (Table 1). Using a small number of regions with a prescribed prior flux pattern inside the regions imposes "hard" constraints on the system (that may lead to "aggregation errors"; Kaminski et al., 2001), which potentially bias the observational error budget and the regional flux estimates. Hence, most inversions solve for increased numbers of regions (40-168). On the other hand, considering all grid cells as unknown fluxes relies heavily on additional "regularization constraints". For instance, LSCEa, MACC-II, and JENA use spatial error correlations (matrix B, Eq. 2) for land and ocean pixels separately, decreasing with distance, to account for effective flux error correlations. However, they follow different philosophies linked to the use of different prior models (Rödenbeck, 2005 for JENA; Chevallier et al., 2012 for both LSCEa and MACC-II cases) that lead to different correlation lengths: JENA uses larger correlation lengths $(1000 \mathrm{~km}$ and $2000 \mathrm{~km}$ over land and ocean, respectively) compared to LSCEa and MACC-II ( $500 \mathrm{~km}$ and $1000 \mathrm{~km}$, respectively) leading to smoother estimated fluxes from JENA compared to MACC-II (see for instance the mean annual flux distribution for each inversion in Supplement, Fig. S8 or under the web-site https://transcom.lsce.ipsl.fr). The regularization schemes based on correlation length scales significantly reduce the number of degrees of freedom (dof, see Patil et al., 2001) in these grid-cell-based inversions to numbers comparable with but still higher than the region-based inversions. For instance, for the spatial domain, MACC-II has for land fluxes a number of dof (degree of freedom) close to 180 and JENA close to 60, while it is around 80 for CTE2013 and only 11 for $\operatorname{TrC}$. All systems solve for monthly fluxes except
MACC-II, CT2011_oi, CTE2013, and JENA, which solve for weekly fluxes. These systems also use additional temporal error correlations for sub-monthly time steps (see Supplement). MACC-II also distinguishes between daytime and nighttime fluxes.

\subsubsection{Prior flux information}

The participating systems use diverse priors for biosphere, ocean and fossil fuel fluxes and prior errors (Supplement, Figs. S3 and S5, for prior land/ocean continental fluxes). For the land, all use net $\mathrm{CO}_{2}$ fluxes from terrestrial ecosystem models with carbon pools brought to equilibrium and thus only weak annual mean carbon uptake (i.e., due to climate changes during the transient simulation), except JENA which uses a more conceptual approach (Rödenbeck et al., 2003). Moreover, only CT2011_oi and CTE2013 use land priors that vary from year to year, including fire disturbances to the land biosphere following the GFED2 approach (van der Werf et al., 2006). The associated prior errors vary between the systems with the LSCEa, MACC-II and JENA cases using spatial error correlations (see above). In most inversions larger uncertainties are applied to land regions than ocean regions. For the sea-air exchange, most systems use climatological priors based on the $\mathrm{pCO}_{2}$ compilations of Takahashi et al. $(1999,2002,2009)$ except for CT2011_oi and CTE2013 which use priors based on ocean interior inversions (Jacobson et al., 2007), and JENA which combines different information (see Supplement for details).

The fossil fuel $\mathrm{CO}_{2}$ flux used as an imposed boundary condition in each inversion contains differences amongst inversions of up to $\pm 8-9 \%$ in annual global totals. There are different fossil fuel $\mathrm{CO}_{2}$ estimates available to the inversion community and different approaches to distributing the fluxes in space and time (sub-annually). Although most systems used EDGAR, CDIAC or BP statistics, JENA has the largest global fossil fuel emissions while the others are generally a little lower than the recent EDGAR v4.2 estimates (Fig. 2a). One reason for the discrepancy may be choices over which categories of emissions are included in the compilations used by any given inversion. Regionally, the differences 

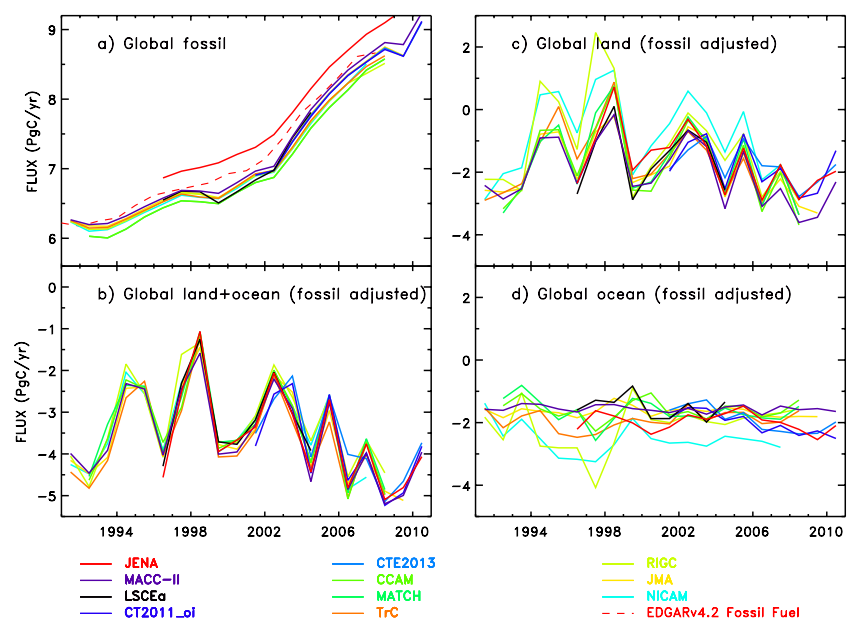

Fig. 2. Annual mean posterior flux of the individual participating inversions for (a) fossil fuel emission, (b) natural "fossil-fuelcorrected" global total carbon exchange, (c) natural "fossil-fuelcorrected" total land and (d) natural "fossil-fuel-corrected" total ocean fluxes.

can be much larger depending on the approach used by the different groups to scale a given gridded emission to globalor country-based total emission statistics (not shown). These differences will manifest as differences in the estimated natural flux since the inversions only constrain the total (fossil + natural) flux from a region and assume no uncertainty in the fossil fuel estimate. Thus some of the natural flux differences between inversions could be artefacts from the differences in the fossil fuel $\mathrm{CO}_{2}$ flux. We consider this as a component of general model-to-model differences and a reflection of actual uncertainty in fossil fuel emissions not yet accounted for in the individual inversions. However, to facilitate comparisons between inversions, we have normalized the "natural" fluxes to account for fossil fuel differences (see Sect. 3.3 below).

\subsubsection{Inverse method}

Although all inversions use a Bayesian formalism with Gaussian errors for fluxes and data, the optimization is done by different algorithms. Many systems limit the number of unknowns in order to be able to directly compute the optimal set of fluxes and their uncertainties, using a classical analytical formulation (Tarantola, 1987; Rodgers, 2000). By contrast, MACC-II and JENA use a 4-dimensional variational approach (4-D-var) derived from 4-D-var systems of numerical weather prediction (Courtier et al., 1994) to iteratively search for the optimal fluxes. These are efficient in the main estimation step, but need considerable extra iterations to derive elements of the posterior flux error covariance matrix or need to be combined with Monte Carlo methods (as is done in MACC-II). Finally, CT2011_oi and CTE2013 restrict the size of the problem using a Kalman smoother approach with a 5-week moving window. In this approach the fluxes are exposed to only 5 weeks of atmospheric constraints, which results in a slow spin-up of the system and may impact more significantly the estimated fluxes for the first year (excluded from the current analysis), than the other inversions.

\subsection{Participant submission processing and flux definition}

Though the results reported by different participants were submitted at a variety of spatial resolutions, results were resampled onto a common $1^{\circ} \times 1^{\circ}$ grid (corresponding to the highest transport model resolution). This facilitated more direct comparisons between the inversion results. Once regridded, the results have been aggregated (i) to land and ocean regions consistent with the RECCAP regional divisions described in Canadell et al. (2011) and (ii) to larger scale totals (northern land, tropical ocean, etc) which are the focus of this paper.

A few technical complications arise with the aggregated totals. First, some submissions report solutions to the inverse problem at spatial scales larger than the RECCAP regional divisions. In this case, wherever possible, we have attempted to use any spatial information implicit in the inversion to aid in the down-sampling. For example, many inversions prescribe a flux distribution within a region when defining the basis function for each of the regions solved for. For example, $\operatorname{TrC}$ assumes land region fluxes are distributed according to CASA model estimates of net primary production (Randerson et al., 1997). Similar approaches were used by all inversion systems except LSCEa, MACC-II and JENA (being grid-cell-based inversions).

Second, each system has its own description of land/sea boundaries, based on the resolution of the transport model they use. After re-gridding, the application of common regional masks may not be compatible with the original land/sea mask of the system, which could bias the aggregated regional flux estimates. We minimize this problem by extending the land (respectively the ocean) regional masks, provided that the land and ocean fluxes were submitted as separate variables. For each land region we included the neighboring pixels over adjacent ocean regions, and conversely for an ocean region.

\subsubsection{Posterior flux definition}

Because different inversion systems utilize different approaches to define the prior fluxes and other boundary condition information, some care must be taken to properly quantify what flux estimate is being compared across the inversion submissions. In this study, "natural" flux is defined as the total flux (all land, ocean, fossil) minus the fossil fuel flux used in the individual inversion submissions. Land use change related carbon fluxes, often accompanied by fires, are thus included in the natural land fluxes reported here. 
However, as noted above, significant differences in prescribed fossil fuel emissions may complicate the intercomparison of the estimated "natural" fluxes. In order to minimize this problem, we choose to "adjust" the natural land/ocean fluxes in order to account for these differences. We thus took the total surface-to-atmosphere gridded flux from each inversion and subtracted a common fossil fuel flux in order to obtain "fossil-corrected" natural land and ocean components (as in Schulze et al., 2010). For the reference fossil fuel emission, we took the recent annual gridded fluxes from EDGARv4.2. The underlying hypothesis is that the atmospheric data constrain the total net surface flux so that extra fossil fuel emissions in a particular land region would be compensated by an increase of the natural land uptake of similar magnitude in that region, through the inversion. Note that such correction is only strictly valid at the global scale. At the regional scale, given the spatial and temporal pattern differences between "natural" and fossil fuel components in the inversion systems, such flux compensation may take place over a different region. This has been illustrated with the LSCEa system by Peylin et al. (2011). In this paper, we mainly discuss large-scale total fluxes (hemispheric or continental) where the correction should remain valid. However, at the finer scale of the RECCAP regions, the fossil fuel correction should be handled with more care. Finally, most regional RECCAP analyses did not use the "fossil fuel correction" and several participating inversions revised their fossil fuel emission during the RECCAP exercise.

\subsubsection{Flux processing}

In this paper we mainly discuss the results aggregated in space and time. For the temporal scales we investigate separately the long-term mean, the inter-annual variations (IAV), the long-term trend, and the mean seasonal cycle.

For the long-term mean, since the inversions have been run for different time periods (the time period was not prescribed), identifying a common time period reduces the intercomparison time span for calculating multi-year means. We choose the 2001-2004 period included by all inversions, though this short period will still be considerably affected by interannual anomalies of these years. The IAV represent annual means with the individual inversion's long-term means removed (in this case the long-term mean is defined over the entire submitted model time span). The long-term trend is obtained from the annual total anomalies (i.e. the IAV signal) by further smoothing these anomalies in time with a three-year moving window. The mean seasonal cycle is represented by 12 monthly values for each inversion. Each value is defined as the mean of all values of the considered month over the common period 2001-2004, minus the long-term mean over that period.

\section{Global to continental-scale land and ocean results}

Here we present a series of results for each of the participating inversions aggregated in space and time. We focus on latitudinally aggregated land and ocean totals as well as on a few continental regions (Supplement, Fig. S7). We show each of the submitting inversion posterior flux estimates ("natural" fossil-fuel-corrected flux). For the sake of clarity, we do not display the prior flux estimates. The prior fluxes for a few regions are given in the Supplement (Figs. S3 and S5) to enable examination of the level of atmospheric constraint on the posterior fluxes versus that from prior information.

\subsection{Annual total fluxes}

\subsubsection{Global totals}

Figure 2a displays the global fossil fuel fluxes where significant differences in the prescribed fossil fuel emissions are noteworthy. The JENA fossil fuel fluxes are larger than other inversions by $\sim 0.45 \mathrm{PgC}^{-1}$. Regionally, the differences are proportionally much larger (not shown); for instance over temperate Asia (Transcom region) the fossil fuel emissions range between 2.16 $\mathrm{Pg} \mathrm{C} \mathrm{yr}^{-1}$ for CCAM/MATCH and $2.58 \mathrm{Pg} \mathrm{C} \mathrm{yr}^{-1}$ for JENA in 2004. Consequently, the JENA system requires greater global total carbon uptake by land and ocean to match the atmospheric $\mathrm{CO}_{2}$ growth (Supplement Fig. S1 for the global land + ocean flux). These fossil fuel flux differences show up as an adjustment to the posterior natural fluxes estimated by each inversion system. As described in Sect. 3.3, we have thus corrected for these differences using EDGAR v4.2 emissions as a reference emission. The natural land fluxes discussed below are "fossil-fuelcorrected" fluxes, unless noted otherwise.

The natural "fossil-fuel-corrected" global total carbon exchange (land plus ocean, Fig. 2b) shows considerable agreement across the inversion systems because of the strong constraint supplied by atmospheric $\mathrm{CO}_{2}$ measurements at the global scale due to global tracer mass conservation. The year-to-year variations of the global total flux depicted in Fig. $2 b$ reflect the variations in global atmospheric $\mathrm{CO}_{2}$ growth rate. As expected, they are robust across the different inversions, with large fluctuations associated with the occurrence of El Niño and La Nina conditions. For instance, in 1998, and to a lesser extent in 1995 and 2003, El Niño conditions led to a reduction in carbon uptake by the land ecosystems. However, even with the "fossil fuel" correction, the global annual totals show significant differences, up to $1 \mathrm{Pg} \mathrm{Cyr}^{-1}$, among the different inversions in particular years. The differences are not systematic and reflect differences between atmospheric transport mixing properties, especially the mixing of surface fluxes to the upper atmosphere, as well as differences between inverse approaches and observation data network. For example, both CarbonTracker systems (CT2011_oi/CTE2013) provide similar fluxes in 2001 


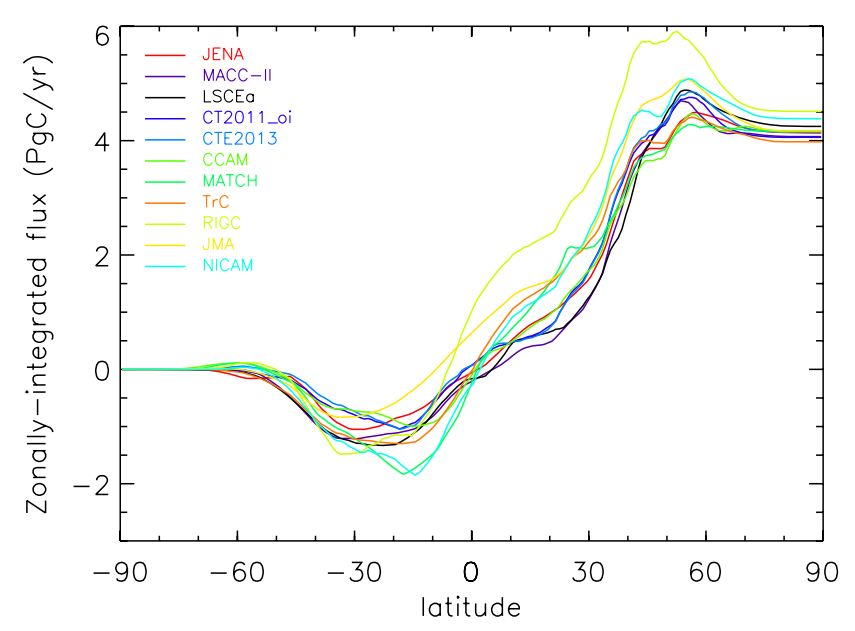

Fig. 3. Zonally integrated total carbon flux (natural land and ocean plus fossil fuel) accumulated from the South to the North Poles for the individual participating inversions averaged over the 2001 to 2004 time period.

and 2002, although lower than all other inversions. Note finally that the differences in the yearly mean may also reflect small differences in flux allocation between December and January (due to the "boxcar" average).

To further investigate the general mean behavior of the participating inversions, Fig. 3 displays the zonally integrated total fluxes (natural land and ocean plus fossil), integrated from south to north for each inversion over the period 2001-2004. This zonally integrated cumulative flux reveals key characteristics of the inverse systems in general and in particular of the transport model used by each inversion. First one can notice that even for a $4 \mathrm{yr}$ period (2001-2004) the total net surface fluxes (values at the North Pole in Fig. 3) differ by up to $0.5 \mathrm{PgC} \mathrm{yr}^{-1}$ (see Sect. 4.2 below). More interestingly, if we assume that all systems provide a reasonable fit to the atmospheric growth rate at all stations, the differences between the shapes of the curve in Fig. 3 could reveal structural differences between the transport models and/or the longitudinal distribution of the total fluxes. For example, the much larger slope between $25^{\circ} \mathrm{S}$ and $25^{\circ} \mathrm{N}$ in RIGC, NICAM and MATCH may indicate that their transport models have different atmospheric mixing over the tropics (stronger) than the other models or that their flux spatial distributions differ. Large differences between the slopes of the integrated fluxes over the tropics $\left(30^{\circ} \mathrm{S}\right.$ to $\left.30^{\circ} \mathrm{N}\right)$ reflect the poor atmospheric constraint over this latitudinal band, while north of $30^{\circ} \mathrm{N}$ the results are in much closer agreement. Overall, the zonally integrated flux diagnostic helps to differentiate and group the participating inversions. For instance, RIGC, NICAM and JMA and to a lesser extent MATCH and $\operatorname{TrC}$ systems have a different north to south flux behavior compared to the other systems.

\subsubsection{Land and ocean totals}

Figure also shows the partitioning between the global land and ocean aggregates (Fig. 2c and d). The major features are:

- The natural land carbon exchange explains most of the total year-to-year flux variations with a strong agreement between all systems, but the annual long-term mean land fluxes differ significantly.

- The natural ocean carbon exchange does not present coherent year-to-year flux variations across the participating inversions, with mean annual flux differences similar to those of the land component (as required to give consistent total land plus ocean flux).

- The shift between the annual mean fluxes across all inversions are relatively constant through the investigated period, indicating that temporal variability is estimated more consistently than longer-term flux averages; although a subset of the inversion systems provide more coherent results at the end of the period (after 2002), potentially linked to the larger atmospheric network.

These results are discussed in more detail in the following sub-sections.

\subsection{Long-term means}

As explained in Sect. 3.3.2, the long-term means are defined for the 2001-2004 period, common to all inversions. Figure 4 displays the total natural fluxes for the globe and three approximately latitudinal bands, as well as the partition between the land and ocean. From the perspective of the longterm mean, the land and ocean (fossil-fuel-corrected) have similar values for global uptake, with the mean flux and standard deviation across inversions giving around $-1.32 \pm 0.39$ and $-1.79 \pm 0.30 \mathrm{PgC} \mathrm{yr}^{-1}$, for land and ocean, respectively. The exceptions is the NICAM inversion, which gives the smallest land uptake (flux $<-0.5 \mathrm{PgC} \mathrm{yr}^{-1}$ ) compensated by the largest ocean sink (flux $\sim-2.5 \mathrm{Pg} \mathrm{Cyr}^{-1}$ ). Note that for the JENA system, the old version used in some RECCAP analyses had a different land/ocean flux partitioning,

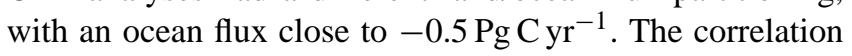
between the time series of the annual total land fluxes and total ocean fluxes (for each inversion) ranges from -0.8 in RIGC to 0.8 in CT2011_oi with four systems having a correlation below 0.3 (JENA, MACC-II, LSCEa, and TrC). High positive or negative values may indicate the difficulties of the atmospheric inversion to separate land and ocean fluxes.

When analyzed in latitudinal bands, the mean "natural" flux across the inversions results in a large total (land plus ocean) sink in the north $\left(-3.4 \pm 0.5 \mathrm{PgC} \mathrm{yr}^{-1}\right)$, a significant source over the tropics $\left(1.6 \pm 0.9 \mathrm{PgC} \mathrm{yr}^{-1}\right)$ and a compensatory sink of similar magnitude in the south 


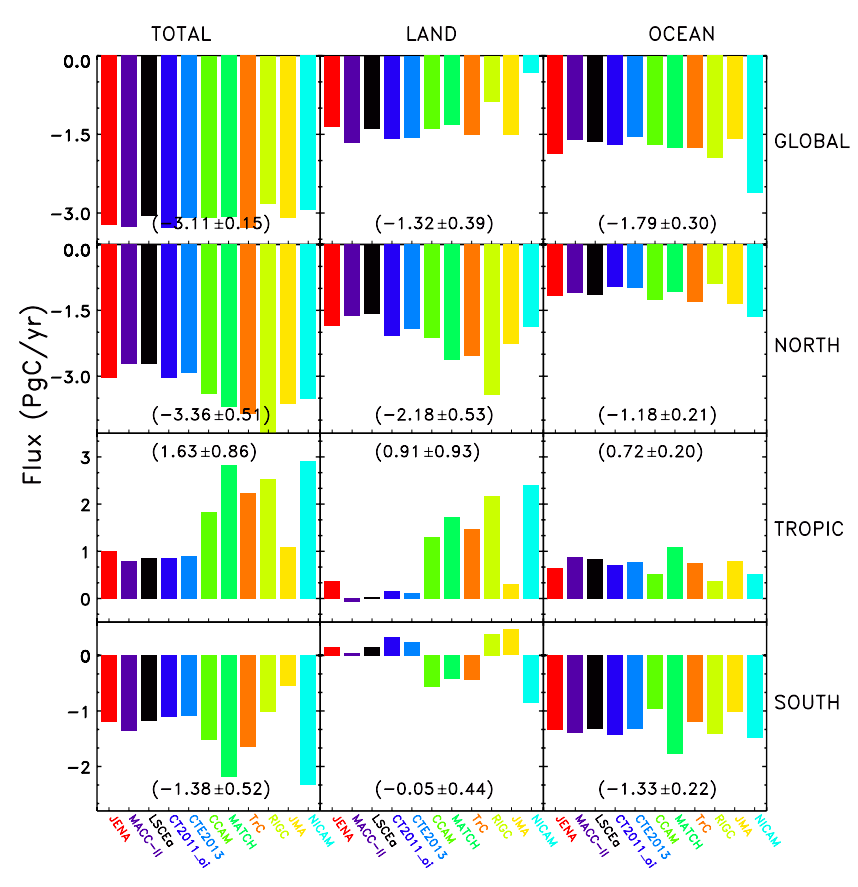

Fig. 4. Mean natural fluxes for the period 2001-2004 of the individual participating inversion posterior fluxes. Shown here are total (first column), natural "fossil-fuel-corrected" land (second column) and natural ocean (third column) carbon exchange aggregated over the Globe (top row), the North (2nd row), the Tropics (3rd row) and the South (bottom row), with the three regions divided by approximately $25^{\circ} \mathrm{N}$ and $25^{\circ} \mathrm{S}$ (but modified over land areas to keep regional estimates (e.g. northern Africa) in one region; see Fig. S7 in Supplement). Numbers in parentheses represent the mean flux and the standard deviation across all inversions.

$\left(-1.4 \pm 0.5 \mathrm{PgC} y r^{-1}\right)$. If we take the median values to be less sensitive to outliers, we obtain similar uptake for the North and South ( -3.4 and $-1.2 \mathrm{Pg} \mathrm{C} \mathrm{yr}^{-1}$, respectively) and a slightly lower tropical source of $1.1 \mathrm{PgC}^{-1}$. The spread between the different inversions at the scale of latitudinal bands is still relatively large. In the north, the MACC-II and LSCEa systems estimate the smallest total carbon uptake $\left(-2.7 \mathrm{PgC}^{-1}\right)$, while RIGC gives the largest uptake

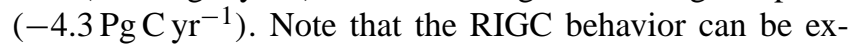
plained by the stronger PBL trapping in the NIES/FRGCG transport model, as shown in Gurney et al. (2004). The spread among the inversions is much greater in the tropics, with a standard deviation close to $0.9 \mathrm{PgC} \mathrm{yr}^{-1}$, reflecting, in part, the low density of atmospheric stations in this region (Fig. 1). In the south, the spread obtained for the total flux is comparable to the north ( $\sigma$ values are close to $0.5 \mathrm{PgC} \mathrm{yr}^{-1}$ for both north and south regions). Finally one should also notice that all inversions neglect the 3-D source of $\mathrm{CO}_{2}$ from the oxidation of reduced carbon compounds in the atmosphere (i.e., source treated as a surface flux) and that such simplification might bias the northern continental land uptake by
$0.2 \mathrm{PgC} \mathrm{yr}^{-1}$ (too large an uptake) as discussed in Suntharalingam et al. (2005).

Two groupings of inversion results arise in the latitudinal aggregate analysis. JENA, LSCE, MACC-II, and the two CarbonTracker results (group 1) provide nearly identical carbon uptake in the south $\left(-1.2 \pm 0.1 \mathrm{Pg} \mathrm{C} \mathrm{yr}^{-1}\right)$ and a carbon release between 0.8 and $1.0 \mathrm{PgC} \mathrm{yr}^{-1}$ in the tropics mostly from the ocean. MATCH, CCAM, TrC, and NICAM inversions (group 2) give a much larger carbon release over the tropics, compensated by a larger uptake in the south and north. RIGC and JMA give moderate to large sources over the tropics but only a small southern carbon sink. It is not clear whether these differences can be attributed to methodological differences in the inversion, since the agreement within the two groups breaks down at continental scale, e.g. in the distribution of the tropical source between Africa, Asia and South America. However, several sources of systematic differences could be envisaged.

With the exception of LSCEa, one difference between the group 1 and group 2 inversions is that group 1 inversions use the atmospheric data at their sampled times as opposed to monthly means. This should allow group 1 inversions to better represent baseline-selected data, whereas group 2 inversions may be allowing baseline-selected data to influence nearby land regions, where no constraint exists in reality. This could result in more variable flux estimates for land regions across group 2 inversions than for group 1 inversions. A second possible source of differences is that group 1 corresponds to inversions that solve for fluxes at the resolution of the transport model or for small ecosystem-based regions over land (both CT systems), with the exception of MATCH and CCAM inversions (group 2) that also solve for a large number of regions. Other potential sources of difference are not systematically associated with group 1 or 2: (i) the prior fluxes do not exhibit systematic differences between group 1 and 2, although $\operatorname{TrC}, \mathrm{MATCH}$, and CCAM impose a large prior deforestation flux over the tropics $\left(\sim 1.5 \mathrm{PgC} \mathrm{yr}^{-1}\right.$; Supplement, Fig. S3), and (ii) there is no clear systematic differences in the transport characteristics between the two groups, in terms of wind field or spatial resolution.

Finally, the division of the total natural fluxes (fossil-fuelcorrected) from each latitude band into land and ocean components (second and third column of Fig. 4) shows that:

- In the north, the land natural sink appears to be twice as large as the ocean sink with a significant spread across the inversions, with the land contributing from around $50 \%$ of the total for NICAM to $80 \%$ of the total for RIGC. The group 1 inversions (the first five systems in each panel of Fig. 4) produce the lowest land sink, around $-1.8 \mathrm{Pg} \mathrm{C} \mathrm{yr}^{-1}$, while the other inversions estimate a much larger land sink, close to $-2.5 \mathrm{Pg} \mathrm{C} \mathrm{yr}^{-1}$.

- In the tropics, all inversions tend to produce a similar ocean carbon source of around $0.7 \mathrm{PgC}^{-1}$ with a relatively small spread $\left(\sigma=0.2 \mathrm{PgC} \mathrm{yr}^{-1}\right)$. Such a 
value does not significantly deviate from the prior ocean fluxes used by the inversions, mostly based on one of Takahashi et al. (1999, 2009) climatologies (See Supplement, Fig. S5, with values between 0.5 and $0.9 \mathrm{Pg} \mathrm{Cyr}^{-1}$ for all inversions). On the other hand, the land natural carbon exchange shows a large spread across all participating inversions, with a mean positive flux to the atmosphere of $0.9 \mathrm{PgC} \mathrm{yr}^{-1}$ but with a standard deviation that is of the same size, i.e. $0.9 \mathrm{Pg} \mathrm{Cyr}^{-1}$. However, group 1 inversions present a much smaller land carbon source or a small land sink (flux between -0.05 and $+0.46 \mathrm{Pg} \mathrm{Cyr}^{-1}$ ). For these inversions, the tropical ecosystems store carbon at a rate that would compensate the emissions through deforestation, i.e., on the order of 1.4 $\mathrm{Pg} \mathrm{C} \mathrm{yr}^{-1}$ (Houghton, 2008). Note that the net deforestation carbon flux is still highly uncertain as a large part of the total biomass burning flux comes from burning of savannah and grasslands, which subsequently regrow. Overall, the strong atmospheric vertical diffusivity in the tropics due to convection, combined with generally under-observed $\mathrm{CO}_{2}$ distribution, explain the larger inversion spread.

- In the south, all inversions produce a large ocean carbon uptake, with a flux around $-1.3{\mathrm{PgC} \mathrm{yr}^{-1}}^{-}$and a relatively small spread. Note that the prior ocean flux ranged from $-1.8{\mathrm{PgC} \mathrm{yr}^{-1}}^{\text {(4 inversions) to }}$ $-1.1 \mathrm{Pg} \mathrm{C} \mathrm{yr}^{-1}$ (4 inversions) but that inversions starting with small or large priors span the full range of posterior flux estimates. Over land, the inversions do not agree on the sign of the natural flux, varying from -0.6 to $+0.5 \mathrm{Pg} \mathrm{C} \mathrm{yr}^{-1}$.

Finally, we briefly investigate the long-term mean natural fluxes within continental/basin-scale subdivisions of the Northern Hemisphere where the atmospheric network is denser: North America, Europe, North Asia, North Atlantic and the North Pacific (Fig. 5). The region boundaries are shown in Supplement, Fig. S7. The three land regions show a significant carbon sink, with fluxes from $-0.4 \mathrm{PgC} \mathrm{yr}^{-1}$ over Europe to $-1.0 \mathrm{PgC} \mathrm{yr}^{-1}$ over North Asia. A large spread among the inversions remains with standard deviations of up to $0.45 \mathrm{Pg} \mathrm{C} \mathrm{yr}^{-1}$ for each region. When differences in surface area are accounted for, Europe exhibits the greatest land uptake $\left(-40 \mathrm{~g} \mathrm{C} \mathrm{m}^{-2} \mathrm{yr}^{-1}\right)$ and North Asia the smallest $\left(-26 \mathrm{gC} \mathrm{m}^{-2} \mathrm{yr}^{-1}\right)$. For the two ocean basins, the inversions estimate a sink with a flux of -0.5 to $-0.6 \mathrm{Pg} \mathrm{Cyr}^{-1}$ and a smaller spread than found on the land $\left(\sigma=0.1-0.15 \mathrm{Pg} \mathrm{C} \mathrm{yr}^{-1}\right)$. This agreement partly reflects the use of similar prior ocean fluxes in the inversions (see Sect. 3.2.4), with relatively tight errors compared to the land fluxes. The prior fluxes (Supplement, Fig. S5) vary between -0.5 and $-0.7 \mathrm{PgC} \mathrm{yr}^{-1}$ for both the North Atlantic and North Pacific. Expressed per surface unit, the estimated North Atlantic sink $\left(-15 \mathrm{~g} \mathrm{C} \mathrm{m}^{-2} \mathrm{yr}^{-1}\right)$ is $60 \%$ larger than the North Pacific one $\left(-9 \mathrm{~g} \mathrm{C} \mathrm{m}^{-2} \mathrm{yr}^{-1}\right)$. Overall, the longitudinal breakdown of the total northern sink appears to be much more variable than the total flux itself. Statistically, adding the flux variances of the four regions, calculated from the spread of the 11 inversions, would lead to a standard deviation of the Northern Hemisphere total flux of roughly $0.8 \mathrm{Pg} \mathrm{C} \mathrm{yr}^{-1}$, a value significantly larger than that calculated directly from the spread of the 11 Northern Hemisphere totals, 0.5 $\mathrm{Pg} \mathrm{Cyr}^{-1}$ (Fig. 4).

\subsection{Interannual variability}

Figure 6 shows the interannual variability (IAV) for the northern, tropical and southern aggregated land and ocean regions. We refer to these as interannual carbon exchange anomalies (see Sect. 3.3).

All submissions tend to exhibit greater IAV on land versus ocean, particularly in the tropical latitude band. For the 1996-2007 period, the mean across all inversions of the standard deviation of the annual means over land is around $1.06 \mathrm{Pg} \mathrm{C} \mathrm{yr}^{-1}$ versus $0.34 \mathrm{Pg} \mathrm{C} \mathrm{yr}^{-1}$ over the ocean. Over land, we obtain $0.67 \mathrm{Pg} \mathrm{Cyr}^{-1}$ for the tropics and only around $0.38 \mathrm{~g} \mathrm{C} \mathrm{m}^{-2} \mathrm{yr}^{-1}$ for both northern and southern land. This is consistent with i) numerous inversion studies over the past two decades (e.g. Bousquet et al., 2000; Baker et al., 2006) and (ii) several analyses of land ecosystem model results (i.e., Sitch et al., 2008) and ocean model results (i.e., Le Quéré et al., 2000, 2010). Note also that it may reflect in part the tighter prior constraint most inversions apply to ocean regions relative to the land. Within the land aggregates, the tropical land exhibits the greatest amount of interannual variability while for the oceans, greater interannual variability is seen in the Southern Ocean (mainly associated with the 1997/1998 time period).

It is worth noting that only the two CT inversion submissions include interannual variability in their prior fluxes (see Fig. S3 in Supplement). The CT2011_oi/CTE2013 prior flux may be influencing their tropical land estimates in 2006 when this submission shows a carbon exchange anomaly in the tropical land that is more positive than the other submitted results.

The phasing of the carbon exchange anomalies shows consistency among the inversion submissions. For the global total, the peak positive anomaly associated with the large 1997/1998 El Niño event shows RIGC reaching their maxima nearly one year sooner than the other submissions; in the tropics, NICAM also shows a broader peak for this event. This is likely due to the $\mathrm{CO}_{2}$ emission signal from forest fires in Indonesia in 1997 and northern Southeast Asia in 1998 as captured by the upper air measurements between Tokyo and Sydney (see Patra et al., 2005b for sensitivity results and detailed discussions). While some other inversions include these upper air measurements, the choice of inverse set-up (particularly observation and prior errors) may limit the extent to which the data are fitted and consequently the 

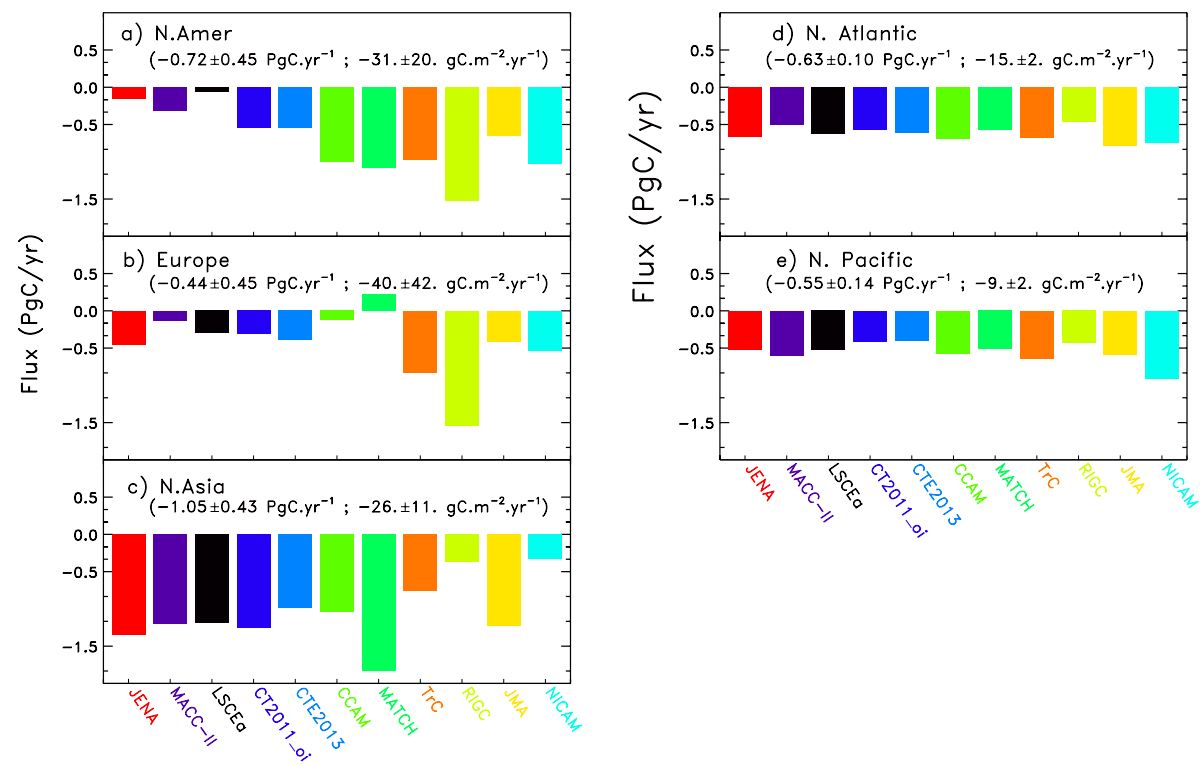

Fig. 5. Same as Fig. 4 but the breakdown of the Northern Hemisphere fluxes into (a) North America, (b) Europe, (c) North Asia, (d) N. Atlantic, and (e) N. Pacific. Numbers in parenthesis represent the mean flux and the standard deviation across all inversions.

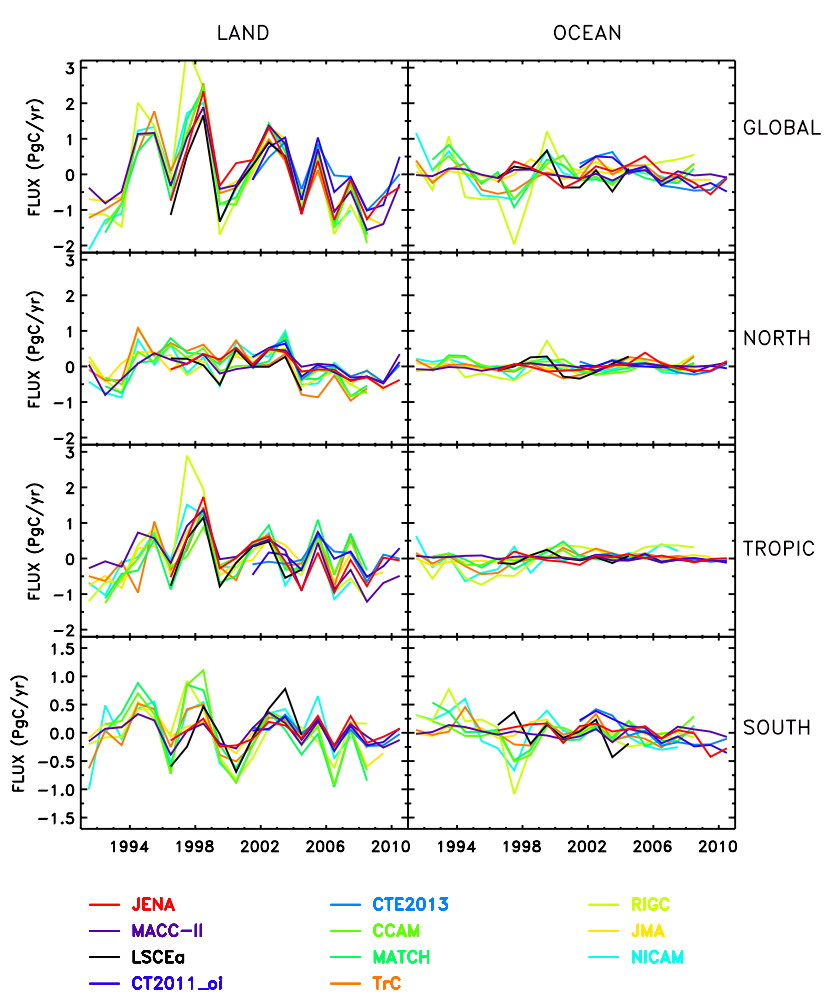

Fig. 6. Annual mean anomalies of the individual participating inversion posterior flux estimates. Shown here are the fossil-fuelcorrected natural land (first column) and natural ocean (second column) carbon exchange for the same regions as Fig. 4: global, north $\left(>25^{\circ} \mathrm{N}\right)$, tropics $\left(25^{\circ} \mathrm{S}-25^{\circ} \mathrm{N}\right)$ and south $\left(<25^{\circ} \mathrm{S}\right)$. magnitude of any emissions estimate from Indonesian fires. Most inversions place the primary driver of the 1997/1998 positive anomaly in the tropical land region though RIGC, CCAM and MATCH also place a positive anomaly in the southern land partly offset by a negative anomaly in the Southern Ocean region. Note that such a negative South-

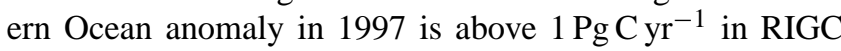
and that it compensates for the large positive tropical land anomaly during the same year.

Overall, the RIGC inversion shows the greatest amount of IAV on land and ocean compared to the remaining inversions. For the 1996-2007 period, the standard deviation of the annual means over land is $1.60 \mathrm{Pg} \mathrm{C} \mathrm{yr}^{-1}$ for RIGC, only $0.93 \mathrm{Pg} \mathrm{C} \mathrm{yr}^{-1}$ for JMA, and between 1.0 and $1.25 \mathrm{Pg} \mathrm{C} \mathrm{yr}^{-1}$ for JENA/MACC-II/CCAM/MATCH/TrC/NICAM inversions. For the shorter 2001-2008 period, both CT inversions show the smallest IAV on land with a standard deviation nearly half that of the remaining inversions $\left(\sim 0.5-0.7 \mathrm{Pg} \mathrm{Cyr}^{-1}\right.$ versus $\left.\sim 1.0 \mathrm{Pg} \mathrm{C} \mathrm{yr}^{-1}\right)$. Differences in the amount of IAV arise primarily from differences in prior flux uncertainties as well as in observation errors. For instance, RIGC uses prior uncertainties over ocean regions that are similar to those over land regions (see Table 2), while most other systems have much larger uncertainties over land than over ocean regions. Such a difference probably explains the largest IAV in RIGC. Futher evaluation of the simulated atmospheric concentrations against independent data (i.e. not assimilated) may help to validate the estimated flux IAV from each inversion.

Positive global land anomalies across the submissions occur for the following years: 1995, 1997/1998, 2002/2003, $2005 / 2006$, and 2007/2008. All of these positive anomalies 
appear to be driven by the tropical land region though the $2002 / 2003$ anomaly shows potential contributions from the northern and southern land as well.

Ocean interannual variability shows less consistency among the inversions. In the Southern Ocean, all inversions except the LSCEa inversion show uptake during the 1997/1998 time period (JENA shows little anomalous flux over this time period). Inversions with larger ocean uptake often have larger southern land sources through this period, suggesting compensating errors. For instance, RIGC, CCAM and MATCH present a significant anti-correlation between the annual southern-land- and Southern-Ocean-fluxes, around -0.6. Overall the spread across the ocean flux estimates tends to decrease through time. It would be valuable if future work could explore whether this reduction in spread is related to improved atmospheric $\mathrm{CO}_{2}$ networks over time.

\subsection{Long-term trends}

Long-term trends are difficult to determine from this set of inversions for a number of reasons. First, the length of the inversions considered here is at most $21 \mathrm{yr}$, with some inversions less than half this length. Second, as noted above, interannual variations are large, making long-term trends unreliable. In particular, ENSO events such as that of 1997-1998 cause variations with somewhat irregular frequency and magnitude, while the eruption of Mt Pinatubo in 1991 likely influences the early years of those inversions that covered longer time periods. Finally the choice and implementation of the fossil fuel $\mathrm{CO}_{2}$ emission prior could lead to apparent trends, particularly at regional scales.

With these caveats in mind, Fig. 7 displays the long-term annual anomalies obtained from smoothing the IAV signal in time (see Sect. 3.3). Most inversions show a tendency towards increasing land carbon uptake in the global and northern land domains from the late 1990s up to 2008 and then a tendency towards decreasing land uptake. Linear fits to the annual land totals for each inversion give on average an increase of $0.12 \mathrm{PgC} \mathrm{yr}^{-1}$ over the 1995-2008 period (standard deviation of $0.05 \mathrm{PgC}^{-1}$ ) explained mainly by the northern land. The tropical land response is less clear with the 1990s potentially dominated by Pinatubo-related negative anomalies early in the decade and ENSO-related positive anomalies later in the decade. In the 2000s, the tropical land trend exhibits a large spread across the participating inversions, with four inversions showing an increased sink (JENA, MACC-II, RIGC, NICAM). The southern land flux estimates appear to be dominated by periodic behavior rather than a trend. The estimated ocean fluxes are approximately constant in time. However, a relatively small increase of the global ocean uptake in the 2000s is visible in a few inversions (both CT, and to a small extent JMA). Note that in the case of the two CT systems, such a trend was also present in their a priori flux estimates (see Supplement, Fig. S5). Unlike recent ocean flux synthesis combining ocean models and

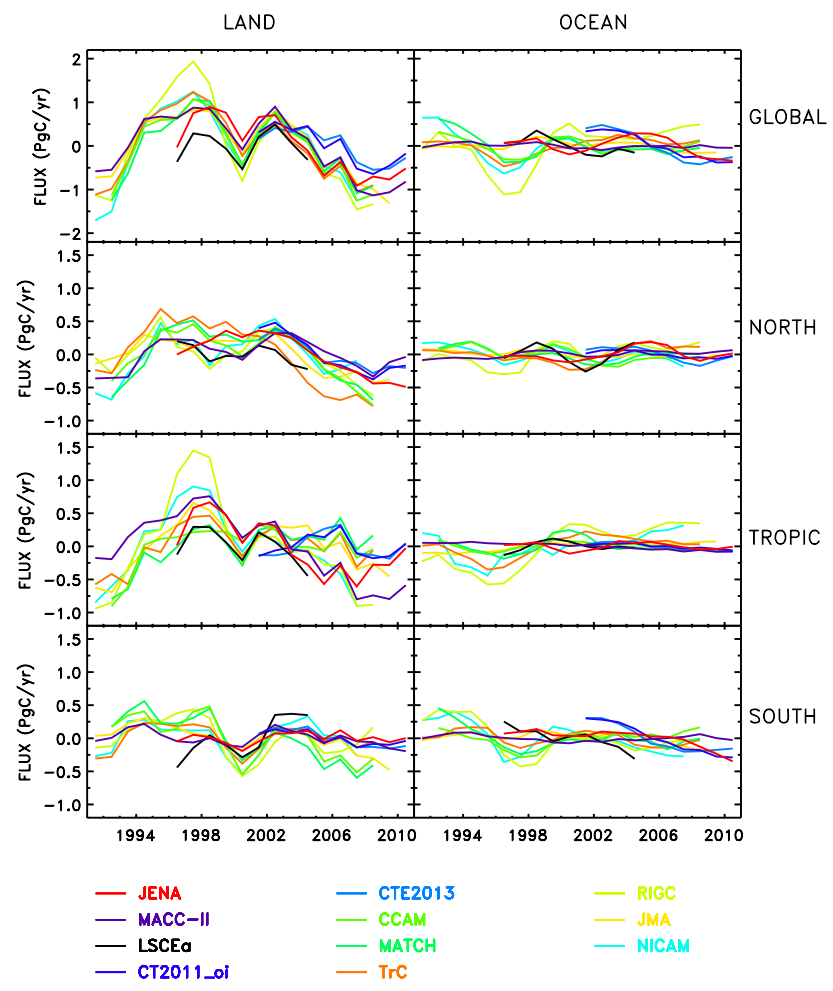

Fig. 7. Smoothed annual mean anomalies (smoothing window of $3 \mathrm{yr}$ ) carbon exchange from the individual participating inversions. Shown here are the natural land "fossil-fuel-corrected" (first column) and natural ocean (second column) carbon exchange aggregated over the Globe, north $\left(>25^{\circ} \mathrm{N}\right)$, tropics $\left(25^{\circ} \mathrm{S}-25^{\circ} \mathrm{N}\right)$ and south $\left(<25^{\circ} \mathrm{S}\right)$.

ocean interior data (i.e., Sarmiento et al., 2010; Wanninkhof et al., 2013) the atmospheric inversions still probably lack the atmospheric observational constraint to unambiguously identify large-scale ocean flux trends.

Figure 8 divides the northern land into regions, showing the three-year smoothed fluxes for North America, Europe and North Asia (see region boundaries in Supplement, Fig. S7). The figure shows a tendency towards increasing land uptake for North Asia from the mid-1990s to 2008 (around $0.7 \mathrm{PgC}$ ), while the European and North American uptake remain more constant. The trend over North Asia tends to reverse after 2008 with a decreasing carbon uptake in JENA, MACC-II and both CT inversions. However, these are all regions with significant fossil fuel $\mathrm{CO}_{2}$ emissions and it is important to understand how these trends could be influenced by how each inversion includes fossil fuel emissions and how the results may be influenced by the fossil fuel correction applied to the results. For example, some inversions use global fossil fuel emissions that increase in time but with a spatial distribution that does not vary over time. Thus the emissions for each region are forced to increase at the same rate. If this did not occur in reality, then any deviation from that global rate would become an artificial trend in the "natural" flux 


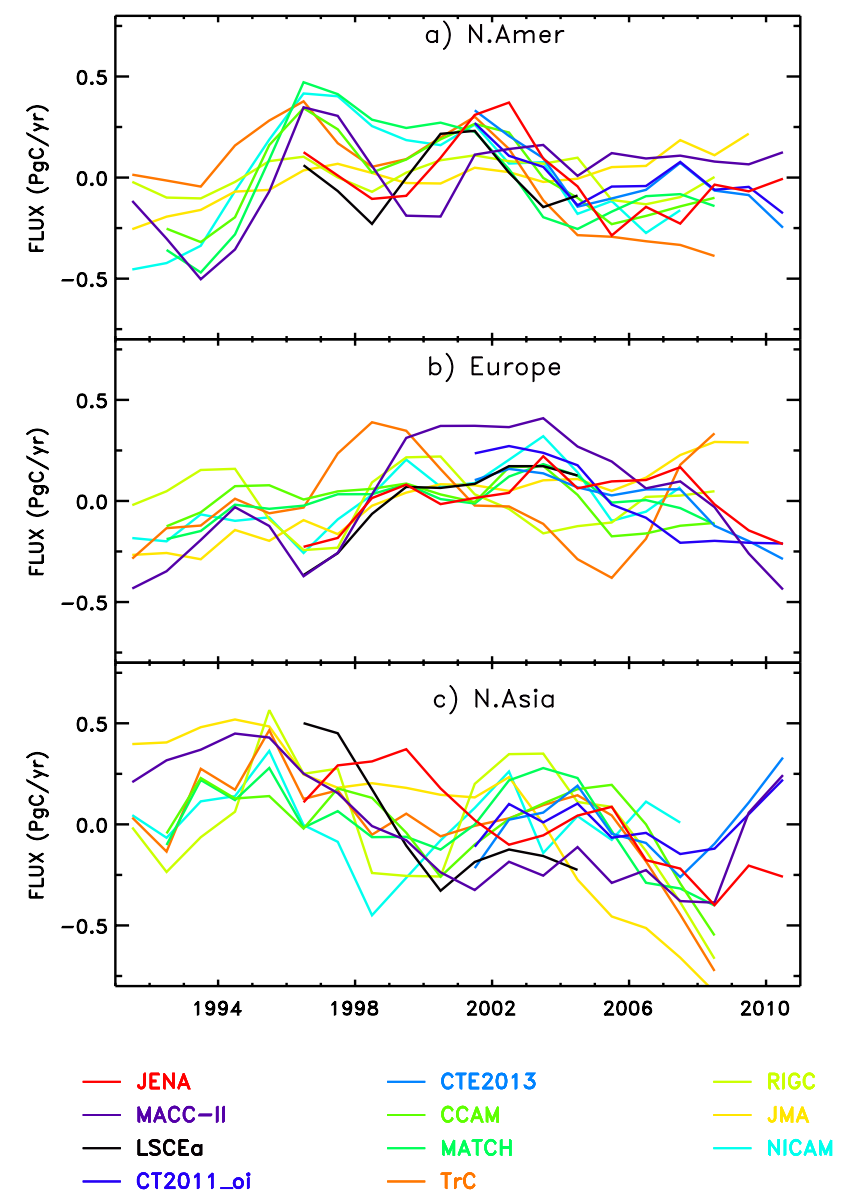

Fig. 8. Same as Fig. 7 but with a breakdown of the northern land fluxes into (a) North America, (b) Europe, and (c) North Asia.

estimated for that region. Note that without the "fossil fuel correction" the smoothed fluxes for North Asia have a larger spread and do not exhibit an increasing carbon uptake from the mid 1990s to 2008 (not shown).

\subsection{Mean seasonal cycle}

Figures 9 and 10 show the mean seasonal cycle (defined in Sect. 3.3) on land and ocean for the latitudinal aggregate regions and for three continental regions. Note that the land and ocean panels use different vertical scales. For this diagnostic, we consider the raw natural fluxes and not the "fossil-fuelcorrected" fluxes, to avoid any spurious monthly flux corrections, given that some inversions use monthly variations in fossil fuel emission. The global land seasonality is driven by the northern land with close agreement regarding both the magnitude and phasing of the growing season and dormant season fluxes. We next discuss, in more detail, the results for each region and for the continental breakdown of the northern land aggregate.

For northern land, the amplitude of the seasonal cycle is close to $3.2 \mathrm{PgC}$ month $^{-1}$ (RIGC having the smallest

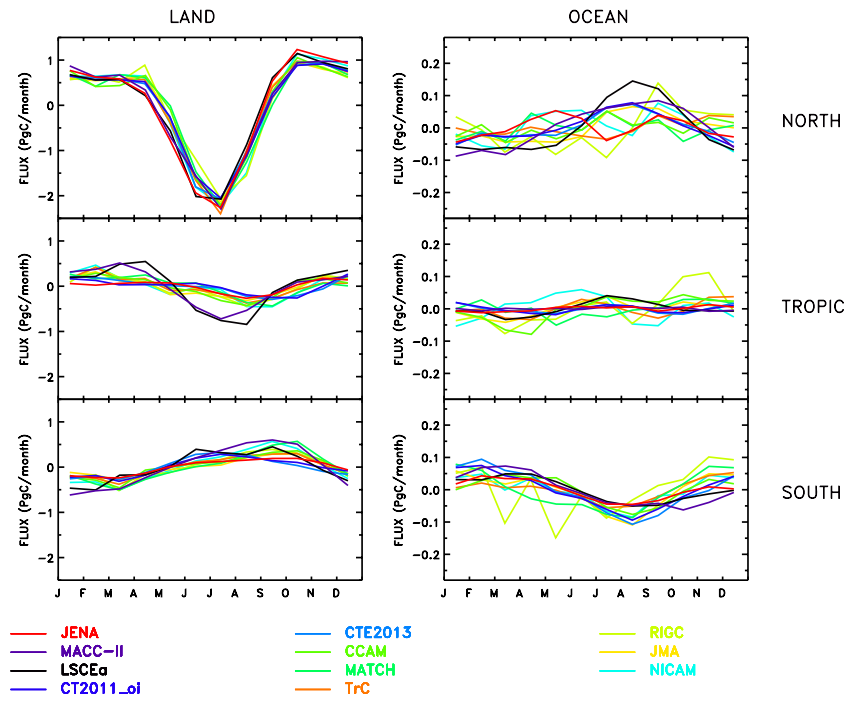

Fig. 9. Mean seasonal cycle of the posterior carbon exchange for the individual participating inversion submissions. Shown here are the natural land (first column) and natural ocean (second column) carbon exchange aggregated over the Northern Hemisphere $\left(>25^{\circ} \mathrm{N}\right)$, the tropics $\left(25^{\circ} \mathrm{S}-25^{\circ} \mathrm{N}\right)$ and the Southern Hemisphere $\left(<25^{\circ} \mathrm{S}\right)$.

amplitude with $3.0 \mathrm{PgC}$ month $^{-1}$ and $\operatorname{TrC}$ the largest with $3.5 \mathrm{Pg} \mathrm{C}_{\text {month }}{ }^{-1}$ ) and the peak of the growing season is located in July for all inversions. The growing season shows a larger spread across the inversions than the dormant season with the LSCEa, MACC-II and JENA systems having a slightly earlier onset of the growing season carbon drawdown than the other systems. The peak carbon uptake is greatest for the $\operatorname{TrC}$ and NICAM inversions with the NICAM inversion compensating somewhat through slightly greater dormant season fluxes. Ocean flux seasonal cycles show less agreement in both phase and magnitude across the inversions. The prior ocean fluxes for this region tend to show carbon release in the July-September period (Supplement, Fig. S6); this seasonality is maintained by some of the inversions, while others (e.g. JENA, TrC, RIGC) show a small uptake during summer. Since the amplitude of the northern ocean seasonality is much smaller than that of the land, a small error in the allocation of seasonality between land and ocean regions can more easily change the phase of the estimated ocean seasonality between inversions than that of the land seasonality.

Seasonality for the tropical land is smaller than the northern land, with most inversions giving maximum uptake around August to October. The LSCEa and MACC-II inversions give larger amplitude seasonality with maximum uptake earlier in the year, from June-August. The constraint from the prior ORCHIDEE land surface model used by the LSCEa/MACC-II inversions is the likely source of this difference (Supplement Fig. S6), given the similarities between the prior and posterior fluxes that we obtain for most 


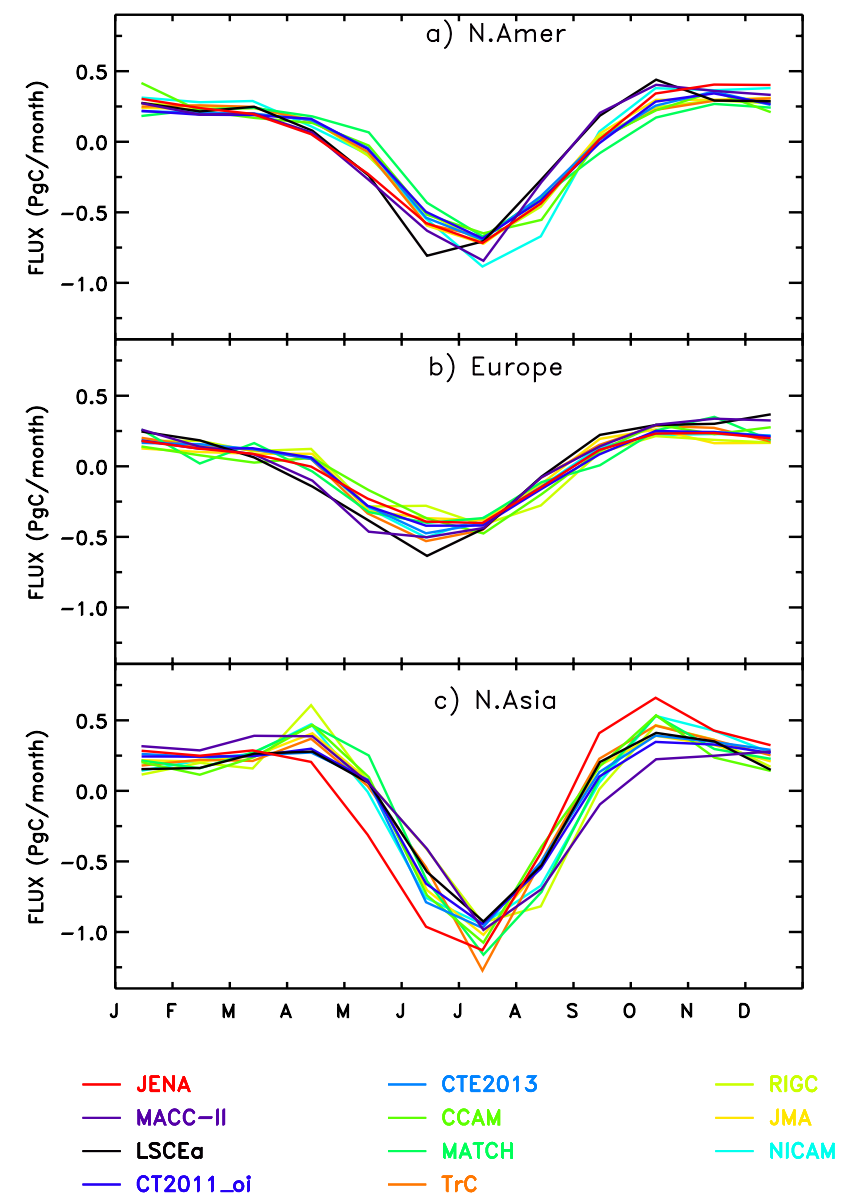

Fig. 10. Same as Fig. 9 but the breakdown of the land Northern Hemisphere fluxes into (a) North America, (b) Europe, and (c) North Asia.

inversions. The seasonality of the tropical oceans shows much smaller amplitude than the tropical land and with less agreement in phase and magnitude. NICAM and RIGC inversions show larger emission peaks than other inversions, in May/June and October/November, respectively, a feature probably linked to larger prior ocean flux uncertainties for RIGC (0.8 $\mathrm{Pg} \mathrm{C} \mathrm{yr}^{-1}$, see Table 2$)$.

Seasonality in the southern land shows reasonable consistency across the inversions in terms of phasing. Maximum carbon uptake across the inversions spans the February to April time period. The peak of the dormant season carbon emission varies from June to October depending upon the inversion. Both CT variants show the earliest peak in dormant season fluxes (roughly June) while MATCH, RIGC, CCAM, JENA and JMA show peak fluxes in October. LSCEa has two emission peaks in June and September. Southern Ocean fluxes show general agreement with uptake in the austral winter/spring, opposing the seasonality of the southern land. The amplitude of the estimated ocean seasonality is larger than in the prior flux, but with similar phasing. The RIGC in- version gives large monthly variations from February to June, not seen in any other system.

Figure 10 shows the seasonality of estimated fluxes for North America, Europe and North Asia. There is broad agreement between the inversions for each region, all showing characteristically different patterns of seasonality between regions. Uptake begins earlier for Europe than for the other regions, while North Asia shows the largest seasonality, because this is the largest land area of the three regions. These differences are also seen in the prior fluxes (Supplement, Fig. S6) used by most inversions, which are mainly based on the CASA model (Randerson et al., 1997). It is worth noting that the inversions that do not use this prior (MACC-II, LSCEa, JENA) nevertheless largely agree with the other inversion estimates. Given the significant differences between the MACC-II/LSCEa prior (both based on two versions of the same land model) and the other priors (Supplement, Fig. S6), the similarity of the posterior fluxes indicates that the seasonality is driven primarily by the atmospheric data rather than the prior flux. A weak influence from the prior may be the reason why both LSCEa and MACC-II inversions show earlier maximum uptake in the North American and European regions.

For Europe there seems to be greater inversion spread for the early part of the growing season than for the onset of senescence. For North Asia, some inversions show increased sources in April-May and September-November. The peak uptake in July-August is more variable across inversions for this region than for the other northern land regions. This is most likely because this region is large (encompassing the Middle East, India, parts of China and Siberia) and is not as well sampled by atmospheric measurements as Europe and North America. Note also that the JENA inversion with no prior land flux seasonality tends to produce an earlier start of the growing season net flux, than the other inversions.

The integrals of the growing season net flux (GSNF, i.e., the period when the net flux is negative) and the dormant season net flux (DSNF, i.e., the period when the net flux is positive) vary significantly between the inversions. For the GSNF/DSNF, the mean and standard deviation across the inversions, calculated for the 2001-2004 period, are: $-2.12 \times 0.21 / 1.45 \times 0.36 \mathrm{PgC}$ for North America, $-1.47 \times 0.21 / 1.08 \times 0.27 \mathrm{Pg} \mathrm{C}$ for Europe, and $-2.68 \times 0.31 / 1.66 \times 0.29 \mathrm{PgC}$ for North Asia. The DSNF appears to be slightly more variable across the inversions than the GSNF.

\section{Interpretation of regional fluxes and uncertainty estimates}

Analysis of the estimated inversion natural fluxes has shown that differences occur at the global scale through different representations of fossil fuel emissions, and that differences between inversions generally increase as the region being 
considered decreases in size. For the regions being used in the RECCAP project, the following issues should be considered when comparing flux estimates across inversions.

1. The availability of atmospheric $\mathrm{CO}_{2}$ data for the individual regions varies greatly. North America and Europe are reasonably well sampled while many regions in the tropics and Southern Hemisphere are poorly constrained by the current $\mathrm{CO}_{2}$ network. The continuity of measurements over the inversion period also needs to be considered. When measurement sites are sparsely distributed and where background $\mathrm{CO}_{2}$ gradients are small (as in the Southern Hemisphere), the inversions can become sensitive to data quality. Differences in the list of sites used by an inversion, and the data uncertainties applied to those sites, can make significant differences to the flux estimates produced by an inversion. For example, anomalously large uptake in the Southern Ocean in 2003 appears to be driven by a single site (JBN, see Lenton et al., 2013). While this was inferred by comparing inversions that did or did not include this site, extensive sensitivity testing is often required to confirm potential site influences.

2. It is important to understand the impact of baseline selection on flux estimates. Most inversions that use monthly mean $\mathrm{CO}_{2}$ data, use only baseline-selected data but do not attempt to 'baseline-select' the response functions of atmospheric transport. For example, a coastal site is usually selected for oceanic rather than continental air masses, but the inversion will assume that the monthly mean $\mathrm{CO}_{2}$ concentration is made up from contributions from nearby ocean and land regions. Thus the inversion can show an apparent constraint on a land region when none should be applied. The issue of baseline-selected data should be less significant for those inversions that use the atmospheric $\mathrm{CO}_{2}$ measurements at their sampled time, although this assumes that the modelled atmospheric transport is correct at the sample time.

3. Since atmospheric inversions usually include prior information, it is important to understand the influence of this prior information on the flux estimates, especially for regions that are poorly constrained by atmospheric observations. For example, analysis of Australian regional fluxes showed that the estimated flux seasonality was often very similar to the underlying prior flux, as also noted above for the seasonality of the tropical land fluxes. Overall, the inversion fluxes should not be considered as fully independent approaches when compared to land or ocean "bottomup" models.

4. Flux estimates for one region may be difficult to interpret when isolated from the whole inversion. For example, land fluxes are generally larger than ocean fluxes, so that relatively small differences in land flux estimates may be offset by much larger relative differences in nearby ocean regions. For instance, the seasonality and the IAV of the northern ocean fluxes differ significantly between the inversions and this may partly reflect "flux leakage" from the land. As a diagnostic, the correlation between the annual total land and total ocean fluxes is useful; in this particular case, six inversions out of 11 provide correlation above 0.5 in absolute value.

5. It is helpful to understand how the flux resolution of an inversion compares with the region being analysed. For example, if an inversion solves for larger regions than those being analysed, it is important to understand what assumptions are used to provide flux estimates for the analysis region and how any globally specified prior fluxes contribute to this. Understanding the interaction between the flux resolution of the inversion and the observing network is also important. Solving for large regions may make an inversion less sensitive to individual sites (and more sensitive to the prior fluxes) and consequently less vulnerable to any data quality issues; conversely when a network is sparse, a site can influence a much larger region than is realistic.

6. There are many aspects common to subsets of inversions presented here, such as common methodology, common prior information or common pre-processing of the atmospheric observations. Thus the flux estimates from those inversions cannot generally be considered independent of each other and may not provide a complete representation of the uncertainty on any given regional estimate. Common biases are likely to influence many inversions. The components of uncertainty at different space and timescales are discussed by Enting et al. (2012).

Following on the uncertainty issue, Table 2 compares the spread of the selected inversions (standard deviation of the annual fluxes, averaged for the period 2001-2004) with the prior and posterior error (i.e. Bayesian error) for all inversions, for the annual totals of the 22 "Transcom" regions plus a few larger aggregates. In the case of CT2011_oi and TrCom, the posterior error sums the random Bayesian error and the standard deviation of the different variants that were performed (quadratic sum; see Supplement). Though the absolute sizes of the inversion spread and Bayesian uncertainty measures are not directly comparable, their mutual relation across regions tentatively reflects the roles of individual components of uncertainty. First, the standard deviation of the inversion spread is computed from only 11 samples, which will underestimate the "true" standard deviation. Second, one should note that the Bayesian errors do not necessarily correspond to the same time average; for JENA they represent a 
Table 2. Comparison of the annual mean flux uncertainty estimated from the spread of the inverse results (mean over the period 2001-2004 of the standard deviation of the annual flux) with the prior and posterior Bayesian uncertainty (one standard deviation) estimated for all inversions, for the 22 Transcom regions (see http://transcom.project.asu.edu/) plus 9 larger aggregates. Uncertainties are expressed in $\mathrm{Pg} \mathrm{C}^{-1}$. Note that some inversions were not able to provide the uncertainties for some regions (noted "_") and that CT2011_oi as well as TrCom posterior uncertainty includes also an "external error" obtained from the spread of their ensemble of inversions (see Supplement).

\begin{tabular}{|c|c|c|c|c|c|c|c|c|c|c|c|c|c|}
\hline & \multirow[t]{2}{*}{ Region $^{1}$} & \multirow{2}{*}{$\begin{array}{c}\text { Inversion } \\
\text { spread }\end{array}$} & \multicolumn{11}{|c|}{ Bayesian Error (Prior/Poste) } \\
\hline & & & MACC-II & JENA & LSCEa & CT2011_oi* & CTE2013 & CCAM & MATCH & JMA & TrCom* & RIGC & NICAM \\
\hline 1 & Boreal N. America & 0.17 & $0.53 / 0.09$ & $0.18 / 0.08$ & $0.73 / 0.22$ & $1.27 / 0.91$ & $0.68 / 0.37$ & $0.42 / 0.29$ & $0.42 / 0.22$ & $0.35 / 0.31$ & $0.39 / 0.28$ & $0.73 / 0.51$ & $0.35 / 0.12$ \\
\hline 2 & Temperate N. America & 0.49 & $0.84 / 0.22$ & $0.20 / 0.09$ & $0.98 / 0.35$ & $1.53 / 0.90$ & $0.88 / 0.46$ & $0.87 / 0.41$ & $0.87 / 0.40$ & $0.84 / 0.63$ & $0.90 / 0.51$ & $1.50 / 0.72$ & $0.84 / 0.20$ \\
\hline 3 & Tropical S. America & 0.69 & $1.37 / 0.84$ & $0.45 / 0.21$ & $1.75 / 0.92$ & $1.51 / 1.53$ & $0.74 / 0.64$ & $0.82 / 0.54$ & $0.82 / 0.62$ & $1.34 / 1.00$ & $1.34 / 0.80$ & $1.41 / 1.06$ & $1.34 / 0.34$ \\
\hline 4 & Temperate S. America & 0.26 & $0.83 / 0.61$ & $0.18 / 0.12$ & $0.93 / 0.51$ & $1.41 / 1.19$ & $0.83 / 0.76$ & $0.73 / 0.52$ & $0.71 / 0.55$ & $0.87 / 0.78$ & $0.89 / 0.44$ & $1.23 / 0.93$ & $0.87 / 0.31$ \\
\hline 5 & N. Africa & 0.32 & $0.87 / 0.57$ & $0.26 / 0.14$ & $0.97 / 0.65$ & $0.93 / 0.99$ & $0.52 / 0.48$ & $0.78 / 0.56$ & $0.77 / 0.60$ & $0.77 / 0.73$ & $0.77 / 0.53$ & $1.33 / 0.92$ & $0.77 / 0.26$ \\
\hline 6 & S. Africa & 0.53 & $1.00 / 0.61$ & $0.22 / 0.14$ & $1.22 / 0.71$ & $1.44 / 1.03$ & $0.72 / 0.61$ & $0.82 / 0.49$ & $0.81 / 0.67$ & $0.93 / 0.82$ & $0.94 / 0.66$ & $1.41 / 1.05$ & $0.93 / 0.32$ \\
\hline 7 & Boreal Eurasia & 0.37 & $0.85 / 0.23$ & $0.23 / 0.09$ & $0.96 / 0.33$ & $2.60 / 3.41$ & $1.50 / 1.15$ & $0.87 / 0.46$ & $0.87 / 0.43$ & $0.70 / 0.48$ & $0.78 / 0.52$ & $1.51 / 0.85$ & $0.70 / 0.22$ \\
\hline 8 & Temperate Eurasia & 0.60 & $0.80 / 0.35$ & $0.23 / 0.12$ & $0.90 / 0.45$ & $1.21 / 1.36$ & $0.71 / 0.56$ & $1.00 / 0.56$ & $1.00 / 0.51$ & $0.79 / 0.62$ & $0.82 / 0.55$ & $1.73 / 0.99$ & $0.79 / 0.22$ \\
\hline 9 & Tropical Asia & 0.50 & $0.63 / 0.62$ & $0.19 / 0.14$ & $0.76 / 0.68$ & $0.51 / 0.55$ & $0.21 / 0.20$ & $0.50 / 0.43$ & $0.5 / 0.44$ & $0.60 / 0.46$ & $0.60 / 0.54$ & $1.22 / 1.05$ & $0.60 / 0.17$ \\
\hline 10 & Australia & & $0.21 / 0.21$ & $0.09 / 0.08$ & $0.27 / 0.24$ & $0.56 / 0.46$ & $0.34 / 0.31$ & $0.33 / 0.25$ & $0.33 / 0.27$ & $0.32 / 0.24$ & $0.32 / 0.13$ & $0.59 / 0.47$ & $0.32 / 0.09$ \\
\hline 11 & Europe & 0.49 & $0.79 / 0.50$ & $0.20 / 0.06$ & $0.99 / 0.61$ & $1.67 / 1.82$ & $0.93 / 0.55$ & $0.82 / 0.41$ & $0.82 / 0.37$ & $0.70 / 0.53$ & $0.75 / 0.33$ & $1.42 / 1.02$ & $0.70 / 0.15$ \\
\hline 12 & Temperate N. Pacific & 0.16 & $0.42 / 0.24$ & $0.09 / 0.07$ & $0.46 / 0.22$ & $0.43 / 0.39$ & $0.43 / 0.37$ & $0.23 / 0.17$ & $0.24 / 0.17$ & $0.28 / 0.25$ & $0.28 / 0.20$ & $1.16 / 0.68$ & $0.28 / 0.07$ \\
\hline 13 & Tropical W. Pacific & 0.13 & $0.22 / 0.17$ & $0.07 / 0.06$ & $0.27 / 0.15$ & $0.01 / 0.02$ & $0.01 / 0.01$ & $0.14 / 0.13$ & $0.14 / 0.13$ & $0.20 / 0.18$ & $0.21 / 0.15$ & $0.71 / 0.48$ & $0.20 / 0.07$ \\
\hline 14 & Tropical East Pacific & 0.16 & $0.23 / 0.19$ & $0.07 / 0.06$ & $0.28 / 0.14$ & $0.26 / 0.35$ & $0.26 / 0.23$ & $0.17 / 0.13$ & $0.16 / 0.13$ & $0.22 / 0.19$ & $0.22 / 0.13$ & $0.79 / 0.55$ & $0.22 / 0.07$ \\
\hline 15 & Temperate S. Pacific & 0.23 & $0.28 / 0.22$ & $0.08 / 0.06$ & $0.35 / 0.17$ & $0.53 / 0.58$ & $0.53 / 0.46$ & $0.36 / 0.21$ & $0.35 / 0.22$ & $0.38 / 0.32$ & $0.38 / 0.26$ & $1.72 / 0.91$ & $0.38 / 0.08$ \\
\hline 16 & Arctic ocean & 0.08 & $0.11 / 0.06$ & $0.03 / 0.02$ & $0.15 / 0.05$ & $0.21 / 0.21$ & $0.22 / 0.19$ & $0.07 / 0.06$ & $0.08 / 0.07$ & $0.16 / 0.15$ & $0.16 / 0.10$ & $0.37 / 0.32$ & $0.16 / 0.04$ \\
\hline 17 & Temperate N. Atlantic & 0.09 & $0.19 / 0.14$ & $0.06 / 0.05$ & $0.23 / 0.12$ & $0.47 / 0.39$ & $0.47 / 0.39$ & $0.11 / 0.10$ & $0.12 / 0.11$ & $0.18 / 0.17$ & $0.18 / 0.09$ & $0.56 / 0.47$ & $0.18 / 0.07$ \\
\hline 18 & Tropical Atlantic & 0.05 & $0.17 / 0.16$ & $0.05 / 0.05$ & $0.22 / 0.14$ & $0.16 / 0.16$ & $0.16 / 0.15$ & $0.12 / 0.11$ & $0.12 / 0.11$ & $0.18 / 0.17$ & $0.18 / 0.10$ & $0.56 / 0.49$ & $0.18 / 0.06$ \\
\hline 19 & Temperate S. Atlantic & 0.06 & $0.19 / 0.16$ & $0.05 / 0.04$ & $0.22 / 0.13$ & $0.27 / 0.21$ & $0.27 / 0.24$ & $0.14 / 0.12$ & $0.14 / 0.12$ & $0.20 / 0.19$ & $0.20 / 0.07$ & $0.68 / 0.57$ & $0.20 / 0.06$ \\
\hline 20 & Southern Ocean & 0.15 & $0.27 / 0.16$ & $0.09 / 0.05$ & $0.35 / 0.15$ & $0.40 / 0.26$ & $0.40 / 0.30$ & $0.43 / 0.16$ & $0.43 / 0.16$ & $0.46 / 0.30$ & $0.46 / 0.22$ & $2.12 / 1.02$ & $0.46 / 0.04$ \\
\hline 21 & Tropical Indian ocean & 0.09 & $0.19 / 0.18$ & $0.06 / 0.05$ & $0.21 / 0.17$ & $0.13 / 0.14$ & $0.13 / 0.12$ & $0.22 / 0.18$ & $0.21 / 0.19$ & $0.26 / 0.24$ & $0.26 / 0.17$ & $1.05 / 0.76$ & $0.26 / 0.09$ \\
\hline 22 & Temperate Indian ocean & 0.09 & $0.22 / 0.22$ & $0.06 / 0.05$ & $0.24 / 0.19$ & $0.27 / 0.45$ & $0.27 / 0.24$ & $0.16 / 0.13$ & $0.16 / 0.11$ & $0.21 / 0.20$ & $0.21 / 0.16$ & $0.76 / 0.56$ & $0.21 / 0.07$ \\
\hline 23 & Global land + ocean & 0.27 & $3.06 / 0.40$ & $1.01 / 0.07$ & $4.54 /-$ & $4.89 /-$ & $3.06 / 2.28$ & $2.59 / 0.42$ & $2.58 /-$ & $2.76 /-$ & $2.85 / 0.07$ & $1.25 / 0.66$ & $2.76 / 0.03$ \\
\hline 24 & Global land & 0.45 & $2.77 / 0.64$ & $0.97 / 0.22$ & $4.01 /-$ & $4.77 /-$ & $2.76 / 2.02$ & $2.48 / 0.53$ & $2.48 / 0.55$ & $2.62 /-$ & $2.71 / 0.41$ & $1.33 / 0.72$ & $2.62 / 0.25$ \\
\hline 25 & Global Ocean & 0.33 & $0.67 / 0.63$ & $0.29 / 0.22$ & $1.67 /-$ & $1.07 /-$ & $1.31 / 1.05$ & $0.73 / 0.38$ & $0.73 / 0.40$ & $0.88 /-$ & $0.88 / 0.38$ & $1.08 / 0.63$ & $0.88 / 0.25$ \\
\hline 28 & North land $(1,2,7,8,11)$ & 0.56 & $1.72 / 0.33$ & $0.60 / 0.12$ & $2.52 /-$ & $3.87 /-$ & $2.34 / 1.54$ & $1.83 / 0.48$ & - & $1.55 /-$ & $1.67 / 0.89$ & $1.42 / 0.67$ & $1.55 / 0.19$ \\
\hline 29 & North ocean $(12,16,17)$ & 0.23 & $0.35 / 0.18$ & $0.12 / 0.09$ & $0.65 /-$ & $0.67 /-$ & $0.70 / 0.58$ & $0.27 / 0.20$ & - & $0.37 /-$ & $0.37 / 0.27$ & $0.77 / 0.52$ & $0.37 / 0.12$ \\
\hline 26 & Tropical land $(3,5,6,9)$ & 0.96 & $1.99 / 0.82$ & $0.64 / 0.21$ & $2.79 /-$ & $2.34 /-$ & $0.93 / 0.82$ & $1.48 / 0.73$ & - & $1.66 /-$ & $1.91 / 1.25$ & $1.34 / 0.98$ & $1.90 / 0.36$ \\
\hline 27 & Tropical ocean $(13,14,18,21)$ & 0.21 & $0.41 / 0.40$ & $0.14 / 0.12$ & $0.59 /-$ & $0.33 /-$ & $0.38 / 0.33$ & $0.33 / 0.27$ & - & $0.44 /-$ & $0.44 / 0.30$ & $0.80 / 0.58$ & $0.44 / 0.16$ \\
\hline 30 & South land $(4,10)$ & 0.47 & $0.86 / 0.61$ & $0.20 / 0.13$ & $1.08 /-$ & $1.52 /-$ & $1.15 / 1.02$ & $0.78 / 0.53$ & - & $1.31 /-$ & $0.95 / 0.64$ & $1.13 / 0.80$ & $0.93 / 0.31$ \\
\hline 31 & South ocean $(15,19,20,22)$ & 0.24 & $0.49 / 0.42$ & $0.18 / 0.10$ & $0.66 /-$ & $0.77 /-$ & $0.79 / 0.65$ & $0.60 / 0.25$ & - & $0.66 /-$ & $0.66 / 0.32$ & $1.46 / 0.77$ & $0.66 / 0.14$ \\
\hline
\end{tabular}

* CT2011_oi/TrCom posterior errors is the quadratic sum of the estimated Bayesian errors and the spread of the 4/13 inversions variant that they have performed (see Supplement).

The posterior errors can thus be larger than the prior Bayesian error.

3-month period. For CT2011_oi and CTE2013 they only partially account for temporal correlations. For RIGC, the ocean errors start with much larger prior than the other systems, leading to the largest posterior ocean values. These particularities and the differences between the inverse set-up lead to very different Bayesian errors.

On average the JENA errors are almost always the lowest estimates, always lower than the model spread (like the NICAM errors). This is consistent with the fact that the JENA prior errors are also much lower, especially over land regions. On the other hand, the CT2001_oi system provides errors that are much larger (up to five times larger than those from JENA) and larger than the model spread for most regions. The RIGC system also provides larger error than the other systems, especially over ocean with values that are similar to the land region errors. On average the other systems provide errors that are comparable or slightly larger than the model spread. The differences between the inversion posterior errors are mainly due to the choice of prior errors but they can also be partly related to the degree of freedom (dof) of each system, JENA having the lowest dof (60) of this subset of inversions. It is thus difficult to draw general conclusions but if we consider primarily the variations of the errors be- tween the regions (and not the absolute values), the following pictures emerge:

- For land regional totals, the inversion spread is often lower than the Bayesian error for the poorly constrained regions (south America, Africa, tropical Asia, Australia) indicating that for these regions the inversion ensemble may underestimate the uncertainty, due to potential common biases and the use of "relatively" similar priors.

- For ocean regional totals, the spread is lower than most Bayesian error estimates (except the JENA case) for most basins and more specifically for the three Atlantic basins and the two Indian ocean basins, possibly due to limited observations and the large influence of the prior (rather similar across the inversions) for these regions.

- Conversely, using the estimated random error from one inversion may also significantly underestimate the uncertainty of most inversion systems, especially for regions that are relatively well sampled (North America). In this case the Bayesian error may neglect biases 
in the transport or in the inverse set-up that can be crucial.

- For larger latitudinal land/ocean aggregates, the model spread is smaller than some of the Bayesian errors except for the tropical land fluxes. The partition of the land carbon uptake between tropics and extra-tropics is sensitive to the inverse set-up (see Sect. 4.2), a source of uncertainty not captured by the random error.

Overall, the use of an ensemble of inversions provides information on the flux uncertainties that helps with evaluating the realism of the random error. Both error values are not independent; they cannot be added and should thus be considered as complementary diagnostics.

\section{Conclusions}

Analysis of the carbon fluxes estimated by the inversions has shown that there is more consistency between inversions for larger scales and for regions where the atmospheric network is denser, as expected. For example, the interannual variability of global fluxes is robust across inversions (largely driven by ENSO), as is the seasonality of northern land fluxes. Differences in atmospheric transport, in observational constraints, in inversion set-up and partly in fossil fuel emissions leads to a spread across inversions in annual mean fluxes of $\sim 1 \mathrm{Pg} \mathrm{C} \mathrm{yr}^{-1}$, but much larger spread for the tropics where the atmospheric constraint is limited. Differences in tropical flux estimates tend to be compensated by flux differences in the Southern Hemisphere. There is some indication that inversion spread decreases over the analysis period but we have not been able to determine whether this is due to increased atmospheric $\mathrm{CO}_{2}$ data availability over time.

Most inversions split carbon uptake approximately equally between land and ocean. There is greater consistency between inversion estimates of long-term mean carbon fluxes from ocean than from land, likely because most inversions place a tighter constraint on their ocean emissions than those from land. Interannual variations in land fluxes are much larger than for the ocean and tend to show greater consistency across inversions. A similar result is obtained for flux seasonality particularly in the Northern Hemisphere; land flux seasonality is large with good agreement across models while ocean seasonality is small with less agreement relative to the magnitude of the seasonality. Any misallocation of flux seasonality between land and ocean will manifest as larger differences between inversions for ocean than land.

Overall, measured atmospheric $\mathrm{CO}_{2}$ concentration gradients provide strong constraints on the surface fluxes. Given the size and geometry of the current network these constraints, relatively strong at large latitudinal-band scale, loosen with increasing spatial scale. The major findings can be summarized as:
- Most inversions agree quite well on the interannual variations of the land and ocean fluxes. They also agree on the land/ocean partitioning, but this is most likely due to the prior information used for the ocean (fluxes and errors) than to the constraint provided by the atmospheric data. This is truer in the Northern Hemisphere than in the Southern Hemisphere, which highlights the importance of having precise and dense observations.

- Transport errors and lack of constraints make our tropical fluxes highly uncertain, but the considered ensemble of inversions splits into a "near-neutral" group and a "strong-source" group. The former group contains more systems that use actual or co-sampled observations, and a higher space-time resolution to solve fluxes for.

- The largest total land sink in the Northern Hemisphere is nearly unanimously located in the Eurasia domain (predominantly in the boreal zone with a flux of $-0.65 \pm 0.32 \mathrm{Pg} \mathrm{C} \mathrm{yr}^{-1}$ compared to the flux of the temperate zone, $-0.43 \pm 0.51 \mathrm{Pg} \mathrm{Cyr}^{-1}$, while the largest uptake rates per unit area are found over Europe $\left(-40 \pm 42 \mathrm{~g} \mathrm{C} \mathrm{m}^{-2} \mathrm{yr}^{-1}\right)$ versus $-31 \pm 20 \mathrm{~g} \mathrm{C} \mathrm{m}^{-2} \mathrm{yr}^{-1}$ for North America and $-26 \pm 11 \mathrm{~g} \mathrm{C} \mathrm{m}^{-2} \mathrm{yr}^{-1}$ for North Eurasia.

- North America and Europe are robustly identified as land sinks of a magnitude that could exceed $30 \%$ of their fossil fuel emissions.

- Increasing trends in carbon uptake over the period 1995-2008 are nearly unanimously placed in the terrestrial biosphere (assuming fossil fuel trends are correct), with a small ocean increase only present in a few inversions. The atmospheric $\mathrm{CO}_{2}$ network is probably not yet dense enough to confirm or invalidate the increased global ocean carbon uptake, estimated from ocean measurements or ocean models (Wanninkhof et al., 2012).

- This intercomparison leaves plenty of room for further refinement as some model results fall at the edge of expected ranges for the land/ocean partition or the North/Tropic/South partition. For instance, the Northern Hemisphere - Tropical land dipole (near-neutral or a strong source for the tropics, compensated by a larger sink in the north) needs to be resolved.

- Finally and most importantly, this set of results is unique in the sense that they close the year-to-year budget of recently observed $\mathrm{CO}_{2}$ increase in the atmosphere. No bottom-up inventory or other modelling system currently has this capacity and these models are thus our only tools to test our current knowledge of exchange between all carbon pools, due to all processes combined together. 


\section{Supplementary material related to this article is available online at http://www.biogeosciences.net/10/ 6699/2013/bg-10-6699-2013-supplement.pdf.}

Acknowledgements. We first thank all PIs of the atmospheric stations whose data are the principal component of the atmospheric inversions and those who maintain instruments and collect samples (including those whose data is included in ObsPack). We also thank those who put significant work into providing atmospheric data compilations (including Ken Masarie for compiling ObsPack and, previously, GLOBALVIEW-CO2) and hosting data sets (especially WDCGG). Wouter Peters was partly paid from NWO VIDI Grant 864.08.012. RIGC inversion work is partly supported by JSPS/MEXT KAKENHI-A (grant number 22241008). I. T. van der Laan-Luijkx has received funding from the European Union's Seventh Framework Programme (FP7/2007-2013) under grant agreement 283080, project GEOCARBON. Y. Niwa thanks Masaki Satoh, Hirofumi Tomita and other members at RIGC/JAMSTEC, AICS/RIKEN, and at AORI/The University of Tokyo for developing NICAM and thanks also Toshinobu Machida for providing Siberian aircraft data. CCAM inversion work was undertaken as part of the Australian Climate Change Science Program, funded jointly by the Department of Industry, Innovation, Climate Change, Science, Research and Tertiary Education, the Bureau of Meteorology and CSIRO and used the NCI National Facility in Canberra, Australia, which is supported by the Australian Commonwealth Government. For TrC inversion, K. R. Gurney and X. Zhang were supported by the DOE on subaward MPC 35WY; they also thank the contributors to the Transcom 3 Level 2 experiment. Frederic Chevallier's work has been supported by the European Commission under the EU Seventh Research Framework Programme (grant agreement 218793 and 283576, MACC and MACC-II). P. Rayner is in receipt of an ARC Professorial Fellowship (DP1096309). CarbonTracker 2009 results provided by NOAA ESRL, Boulder, Colorado, USA from the website at http://carbontracker.noaa.gov.

Edited by: J. Canadell

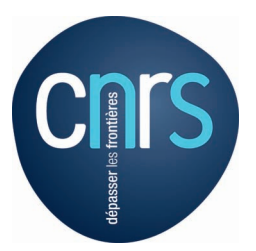

The publication of this article is financed by CNRS-INSU.

\section{References}

Andres, R. J., Gregg, J. S., Losey, L., Marland, G., and Boden, T. A.: Monthly, global emissions of carbon dioxide from fossil fuel consumption, Tellus B, 63, 309-327, doi:10.1111/j.16000889.2011.00530.x, 2011.

Andres, R. J., Boden, T. A., Bréon, F.-M., Ciais, P., Davis, S., Erickson, D., Gregg, J. S., Jacobson, A., Marland, G., Miller, J., Oda, T., Olivier, J. G. J., Raupach, M. R., Rayner, P., and Treanton, K.: A synthesis of carbon dioxide emissions from fossil-fuel com- bustion, Biogeosciences, 9, 1845-1871, doi:10.5194/bg-9-18452012, 2012.

Baker, D. F., Law, R. M., Gurney, K. R., Rayner, P., Peylin, P., Denning, A. S., Bousquet, P., Bruhwiler, L., Chen, Y.-H., Ciais, P., Fung, I. Y., Heimann, M., John, J., Maki, T., Maksyutov, S., Masarie, K., Prather, M., Pak, B., Taguchi, S., and Zhu, Z.: TransCom 3 inversion intercomparison: Impact of transport model errors on the interannual variability of regional $\mathrm{CO}_{2}$ fluxes, 1988-2003, Global Biogeochem. Cy., 20, GB1002, doi:10.1029/2004GB002439, 2006.

Bousquet, P., Peylin, P., Ciais, P., Le Quéré, C., Friedlingstein, P., and Tans, P. P.: Regional Changes in Carbon Dioxide Fluxes of Land and Oceans Since 1980, Science, 290, 1342-1346, doi:10.1126/science.290.5495.1342,2000.

Canadell, J. G., Ciais, P., Gurney, K., Le Quéré, C., Piao, S., Raupach, M. R., and Sabine, C. L.: An International Effort to Quantify Regional Carbon Fluxes, Eos Trans. AGU, 92, 81-82, doi:10.1029/2011EO100001, 2011.

Chevallier, F., Fisher, M., Peylin, P., Serrar, S., Bousquet, P., Bréon, F.-M., Chédin, A., and Ciais, P.: Inferring $\mathrm{CO}_{2}$ sources and sinks from satellite observations: Method and application to TOVS data, J. Geophys. Res., 110, D24309, doi:10.1029/2005JD006390, 2005.

Chevallier, F., Ciais, P., Conway, T.J., Aalto, T., Anderson, B. E., Bousquet, P., Brunke, E. G., Ciattaglia, L., Esaki, Y., Fröhlich, M., Gomez, A. J., Gomez-Pelaez, A. J., Haszpra, L., Krummel, P., Langenfelds, R., Leuenberger, M., Machida, T., Maignan, F., Matsueda, H., Morguí, J. A., Mukai, H., Nakazawa, T., Peylin, P., Ramonet, M., Rivier, L., Sawa, Y., Schmidt, M., Steele, P., Vay, S. A., Vermeulen, A. T., Wofsy, S., and Worthy, D.: $\mathrm{CO}_{2}$ surface fluxes at grid point scale estimated from a global 21 year reanalysis of atmospheric measurements, J. Geophys. Res., 115 , D21307, doi:10.1029/2010JD013887, 2010.

Chevallier, F., Deutscher, N., Conway, T. J., Ciais, P., Ciattaglia, L., Dohe, S., Fröhlich, M., Gomez-Pelaez, A. J., Griffith, D., Hase, F., Haszpra, L., Krummel, P., Kyrö, E., Labuschagne, C., Langenfelds, R., Machida, T., Maignan, F., Matsueda, H., Morino, I., Notholt, J., Ramonet, M., Sawa, Y., Schmidt, M., Sherlock, V., Steele, P., Strong, K., Sussmann, R., Wennberg, P., Wofsy, S., Worthy, D., Wunch, D., and Zimnoch, M.: Global $\mathrm{CO}_{2}$ fluxes inferred from surface air-sample measurements and from TCCON retrievals of the $\mathrm{CO}_{2}$ total column, Geophys. Res. Lett., 38, L24810, 2011.

Chevallier, F., Wang, T., Ciais, P., Maignan, F., Bocquet, M., Arain, A., Cescatti, A., Chen, J.-Q., Dolman, H., Law, B. E., Margolis, H. A., Montagni, L., and Moors, E. J.: What eddy-covariance flux measurements tell us about prior errors in $\mathrm{CO}_{2}$-flux inversion schemes. Global Biogeochem. Cy., 26, GB1021, doi:10.1029/2010GB003974, 2012.

Ciais, P., Canadell, J. G., Luyssaert, S., Chevallier, F., Shvidenko, A., Poussi, Z., Jonas, M., Peylin, P., King, A. W., Schulze, E. D., Piao, S. L., Rödenbeck, C., Peters, W., and Breon, F. M.: Can we reconcile atmospheric estimates of the Northern terrestrial carbon sink with land-based accounting?, Current Opinion In Environmental Sustainability, 2, 225-230, doi:10.1016/j.cosust.2010.06.008, 2010.

Courtier, P., Thépaut, J.-N., and Hollingsworth, A.: A strategy for operational implementation of 4D-VAR, using an incremental approach, Q. J. Roy. Meteor. Soc., 120, 1367-1387, 1994. 
Dargaville, R. J., Law, R. M., and Pribac, F., Implications of internannual variability in atmospheric circulation on modeled $\mathrm{CO}_{2}$ concentrations and source estimates, Global Biogeochem. Cy., 14, 931-943, 2000.

Denning, A.S., Holzer, M., Gurney, K. R., Heimann, M., Law, R. M., Rayner, P. J., Fung, I. Y., Fan, S. M., Taguchi, S., Friedlingstein, Balkanski, P. Y., Taylor, J., Maiss, M., and Levin, I.: ThreeDimensional Transport and Concentration of $\mathrm{SF}_{6}$ : A Model Intercomparison Study (TransCom 2), Tellus B, 51, 266-297, 1999.

Engelen, R. J., Denning, A. S., Gurney, K. R., Law, R. M., Rayner, P.J., Baker, D., Bousquet, P., Bruhwiler, L., Chen, Y.H., Ciais, P., Fan, S., Fung, I.Y., Gloor, M., Heimann, M., Higuchi, K., John, J., Maki, T., Maksyutov, S., Masarie, K., Peylin, P., Prather, M., Pak, B. C., Sarmiento, J., Taguchi, S., Takahashi, T., and Yuen, C. W.: On error estimation in atmospheric $\mathrm{CO}_{2}$ inversions, J. Geophys. Res., 107, 4635, doi:10.1029/2002JD002195, 2002.

Enting, I. G.: Inverse Problems in Atmospheric Constituent Transport, Cambridge University Press, 2002.

Enting, I. G. and Mansbridge, J. V.: Seasonal sources and sinks of atmospheric $\mathrm{CO}_{2}$ : Direct inversion of filtered data, Tellus B, 41, 111-126, 1989.

Enting, I. G., Rayner, P. J., and Ciais, P.: Carbon Cycle Uncertainty in REgional Carbon Cycle Assessment and Processes (RECCAP), Biogeosciences, 9, 2889-2904, doi:10.5194/bg-9-28892012, 2012.

Errico, R. M.: What is an adjoint model?, B. Am. Meteorol. Soc, 78, 2577-2591, 1997.

Evans, S. N. and Stark, P. B: Inverse problems as statistics, Inverse Probl., 18, R55-R97, doi:10.1088/0266-5611/18/4/201, 2002.

Evensen, G.: Data assimilation : The ensemble Kalman filter, Springer, Berlin, 2007.

GLOBALVIEW-CO2, Cooperative Atmospheric Data Integration Project-Carbon Dioxide [CD-ROM], NOAA CMDL, Boulder, Colo, available at: ftp://ftp.cmdl.noaa.gov/ccg/co2/ GLOBALVIEW), (last access: May 2012), 2009.

Gurney, K. R., Law, R. M., Denning, A.S., Rayner, P. J., Baker, D., Bousquet, P., Bruhwiler, L., Chen, Y.H., Ciais, P., Fan, S., Fung, I.Y., Gloor, M., Heimann, M., Higuchi, K., John, J., Maki, T., Maksyutov, S., Masarie, K., Peylin, P., Prather, M., Pak, B. C., Randerson, J., Sarmiento, J., Taguchi, S., Takahashi, T., and Yuen, C. W.: Towards robust regional estimates of $\mathrm{CO}_{2}$ sources and sinks using atmospheric transport models, Nature, 415, 626630, 2002.

Gurney, K. R., Law, R. M., Denning, A. S., Rayner, P. J., Baker, D., Bousquet, P., Bruhwiler, L., Chen, Y. H. Ciais, P., Fan, S., Fung, I. Y., Gloor, M., Heimann, M., Higuchi, K., John, J., Kowalczyk, E., Maki, T., Maksyutov, S., Peylin, P., Prather, M., Pak, B. C., Sarmiento, J., Taguchi, S., Takahashi, T., and Yuen, C. W.: Transcom $3 \mathrm{CO}_{2}$ Inversion Intercomparison: 1. Annual mean control results and sensitivity to transport and prior flux information, Tellus B, 55, 555-579, doi:10.1034/j.16000560.2003.00049.x, 2003.

Gurney, K. R., Law, R. M., Denning, A. S., Rayner, P. J., Pak, B. C., Baker, D., Bousquet, P., Bruhwiler, L., Chen, Y.-H., Ciais, P., Fung, I. Y., Heimann, M., John, J., Maki, T., Maksyutov, S., Peylin, P., Prather, M., and Taguchi, S.: Transcom 3 inversion intercomparison: Model mean results for the estimation of seasonal carbon sources and sinks, Global Biogeochem. Cy., 18, GB1010, doi:10.1029/2003GB002111, 2004.

Gurney, K. R., Chen, Y.-H., Maki, T., Kawa, S. R., Andrews, A., and Zhu, Z.: Sensitivity of atmospheric $\mathrm{CO}_{2}$ inversions to seasonal and interannual variations in fossil fuel emissions, J. Geophys. Res., 110, D10308, doi:10.1029/2004JD005373, 2005.

Gurney, K. R., Baker, D., Rayner, P., and Denning, S., Interannual variations in continental-scale net carbon exchange and sensitivity to observing networks estimated from atmospheric $\mathrm{CO}_{2}$ inversions for the period 1980 to 2005, Global Biogeochem. Сy., 22, GB3025, doi:10.1029/2007GB003082, 2008.

Hayes, D. J., Turner, D. P., Stinson, G., McGuire, A. D., Wei, Y., West, T. O., Heath, L. S., de Jong, B., McConkey, B. G., Birdsey, R. A., Kurz, W. A., Jacobson, A. R., Huntzinger, D. N., Pan, Y., Post, W. M., and Cook, R. B.: Reconciling estimates of the contemporary North American carbon balance among terrestrial biosphere models, atmospheric inversions, and a new approach for estimating net ecosystem exchange from inventory-based data, Glob. Change Biol., 18, 1282-1299. doi:10.1111/j.13652486.2011.02627.x, 2012.

Houghton, R. A.: Carbon Flux to the Atmosphere from Land-Use Changes: 1850-2005, in: TRENDS: A Compendium of Data on Global Change. Carbon Dioxide Information Analysis Center, Oak Ridge National Laboratory, US Department of Energy, Oak Ridge, Tenn., USA, 2008.

Ide, K., Courtier, P., Ghil, M., and Lorenc, A. C.: Unified notation for data assimilation: Operational, Sequential and Variational, J. Met. Soc. Japan, 75, 181-189, 1997.

Jacobson, A. R., Gruber, N., Sarmiento, J. L., Gloor, M., and Mikaloff Fletcher, S. E.: A joint atmosphere-ocean inversion for surface fluxes of carbon dioxide: I. Methods and global-scale fluxes, Global Biogeochem. Cy., 21, GB1019, doi:10.1029/2005GB002556, 2007.

Kalman, R. E.: A new approach to linear filtering and prediction problems, J. Basic Eng.-T ASME, 82, 35-45, 1960.

Kaminski, T., Rayner, P. J., Heimann, M., and Enting, I. G.: On aggregation errors in atmospheric transport inversions, J. Geophys. Res., 106, 4703-4715, 2001.

Law, R. M., Rayner, P. J., Denning, A. S., Erickson, D., Fung, I. Y., Heimann, M., Piper, S. C., Ramonet, M., Taguchi, S., Taylor, J. A., Trudinger, C. M., and Watterson, I. G.: Variations in modelled atmospheric transport of carbon dioxide and the consequences for $\mathrm{CO}_{2}$ inversions, Global Biogeochem. Cy., 10, 783-796, 1996.

Law, R. M., Chen, Y. H., and Gurney, K. R.: Transcom 3 modellers: Transcom $3 \mathrm{CO}_{2}$ Inversion Intercomparison: 2. Sensitivity of annual mean results to data choices, Tellus B, 55, 580-595, doi:10.1034/j.1600-0889.2003.00053.x, 2003.

Law, R. M., Peters, W., Rödenbeck, C., Aulagnier, C. Baker, I., Bergmann, D. J., Bousquet, P., Brandt, J., Bruhwiler, L., Cameron-Smith, P. J., Christensen, J. H., Delage, F., Denning, A. S., Fan, S., Geels, C., Houweling, S., Imasu, R., Karstens, U., Kawa, S. R., Kleist, J., Krol, M. C., Lin, S.-J., Lokupitiya, R., Maki, T., Maksyutov, S., Niwa, Y., Onishi, R., Parazoo, N, Patra, P. K., Pieterse, G., Rivier, L., Satoh, M., Serrar, S., Taguchi, S., Takigawa, M., Vautard, R., Vermeulen, A. T., and Zhu, Z.: TransCom model simulations of hourly atmospheric $\mathrm{CO}_{2}$ : Experimental overview and diurnal cycle results for 2002, Global Biogeochem. Cy., 22, GB3009, doi:10.1029/2007GB003050, 2008. 
Le Quéré, C., Orr, J., Monfray, P., Aumont, O., and Madec, G.: interannual variability of the oceanic sink of $\mathrm{CO}_{2}$ from 1979 through 1997, Global Biogeochem. Cy., 22, GB3009, doi:10.1029/1999GB900049, 2000.

Le Quéré, C., Takahashi, T., Buitenhuis, C. E., Rödenbeck, C., and Sutherland, S.: Impact of climate change and variability on the global oceanic sink of $\mathrm{CO}_{2}$, Global Biogeochem. Cy., 24, GB4007, doi:10.1029/2009GB003599, 2010.

Lenton, A., Tilbrook, B., Law, R. M., Bakker, D., Doney, S. C., Gruber, N., Ishii, M., Hoppema, M., Lovenduski, N. S., Matear, R. J., McNeil, B. I., Metzl, N., Mikaloff Fletcher, S. E., Monteiro, P. M. S., Rödenbeck, C., Sweeney, C., and Takahashi, T.: Seaair $\mathrm{CO}_{2}$ fluxes in the Southern Ocean for the period 1990-2009, Biogeosciences, 10, 4037-4054, doi:10.5194/bg-10-4037-2013, 2013.

Maki, T., Ikegami, M., Fujita, T., Hirahara, T., Yamada, K., Mori, K., Takeuchi, A., Tsutsumi, Y., Suda, K., and Conway, T. J., New technique to analyse global distributions of $\mathrm{CO}_{2}$ concentrations and fluxes from non-processed observational data, Tellus B, 62, 797-809, doi: 10.1111/j.1600-0889.2010.00488.x, 2010.

Maksyutov, S., Machida, T., Mukai, H., Patra, P. K., Nakazawa, T., Inoue, G., and Transcom 3 modelers: Effect of recent observations on Asian $\mathrm{CO}_{2}$ flux estimates by transport model inversions, Tellus B, 55, 522-529, 2003.

Niwa, Y., Machida, T., Sawa, Y., Matsueda, H., Schuck, T. J., Brenninkmeijer, C. A. M., Imasu, R., and Satoh, M.: Imposing strong constraints on tropical terrestrial $\mathrm{CO}_{2}$ fluxes using passenger aircraft based measurements, J. Geophys. Res., 117, D11303, doi:10.1029/2012JD017474, 2012.

Patil, D., Hunt, B., Kalnay, E., Yorke, J., and Ott., E. : Local Low Dimensionality of Atmospheric Dynamics, Phys. Rev. Lett., 86, 5878-5881, doi:10.1103/PhysRevLett.86.5878, 2001.

Patra, P. K., Maksyutov, S., and Transcom 3 modelers: Sensitivity of optimal extension of $\mathrm{CO}_{2}$ observation networks to model transport, Tellus B, 55, 498-511, 2003.

Patra, P. K., Maksyutov, S., Ishizawa, M., Nakazawa, T., Takahashi, T., and Ukita, J.: Interannual and decadal changes in the sea-air $\mathrm{CO}_{2}$ flux from atmospheric $\mathrm{CO}_{2}$ inverse modelling, Global Biogeochem. Cy., 19, GB4013, doi:10.1029/2004GB002257, 2005a.

Patra, P. K., Ishizawa, M., Maksyutov, S., Nakazawa, T., and Inoue, G.: Role of biomass burning and climate anomalies for land-atmosphere carbon fluxes based on inverse modeling of atmospheric $\mathrm{CO}_{2}$, Global Biogeochem. Cy., 19, GB3005, doi:10.1029/2004GB002258, 2005b.

Patra, P. K., Gurney, K.R., Denning, A. S., Maksyutov, S., Nakazawa, T., Baker, D., Bousquet, P., Bruhwiler, L., Chen, Y.H., Ciais, P., Fan, S., Fung, I., Gloor, M., Heimann, M., Higuchi, K., John, J., Law, R. M., Maki, T., Pak, B. C., Peylin, P., Prather, M., Rayner, P. J., Sarmiento, J., Taguchi, S. Takahashi, T., and Yuen, C. W.: Sensitivity of inverse estimation of annual mean $\mathrm{CO}_{2}$ sources and sinks to ocean-only sites versus allsites observational networks, Geophys. Res. Lett., 33, L05814, doi:10.1029/2005GL025403, 2006.

Patra, P. K., Houweling, S., Krol, M., Bousquet, P., Belikov, D., Bergmann, D., Bian, H., Cameron-Smith, P., Chipperfield, M. P., Corbin, K., Fortems-Cheiney, A., Fraser, A., Gloor, E., Hess, P., Ito, A., Kawa, S. R., Law, R. M., Loh, Z., Maksyutov, S., Meng, L., Palmer, P. I., Prinn, R. G., Rigby, M., Saito, R., and Wilson, C.: TransCom model simulations of $\mathrm{CH}_{4}$ and related species: linking transport, surface flux and chemical loss with $\mathrm{CH}_{4}$ variability in the troposphere and lower stratosphere, Atmos. Chem. Phys., 11, 12813-12837, doi:10.5194/acp-11-12813-2011, 2011.

Peters, W., Miller, J. B., Whitaker, J., Denning, A. S., Hirsch, A., Krol, M. C., Zupanski, D., Bruhwiler, L., and Tans, P. P.: An ensemble data assimilation system to estimate $\mathrm{CO}_{2}$ surface fluxes from atmospheric trace gas observations, J. Geophys. Res., 110, D24304, doi:10.1029/2005JD006157, 2005.

Peters, W., Jacobson, A. R., Sweeney, C., Andrews, A. E., Conway, T. J., Masarie, K., Miller, J. B., Bruhwiler, L., M. P., Pétron, G., Hirsch, A. I., Worthy, D. E. J., van der Werf, G. R., Randerson, J. T., Wennberg, P. O., Krol, M. C., and Tans, P. P.: An atmospheric perspective on North American carbon dioxide exchange: CarbonTracker, P. Natl. Acad. Sci. USA, 104, 1892518930, doi:10.1073/pnas.0708986104, 2007.

Peters, W., Krol, M. C., van der Werf, G. R., Houweling, S., Jones, C. D., Hughes, J., Schaefer, K., Masarie, K. A., Jacobson, A. R., Miller, J. B., Cho, C.H., Ramonet, M., Schmidt, M., Ciattaglia, L., Apadula, F., Heltai, D., Meinhardt, F., Di Sarra, A. G., Piacentino, S., Sferlazzo, D., Aalto, T., Hatakka, J., Ström, J., Haszpra, L., Meijer, H. A. J., Van der Laan, S., Neubert, R. E. M., Jordan, A., Rodó, X., Morguí, J.-A., Vermeulen, A. T., Popa, E., Rozanski, K., Zimnoch, M., Manning, A. C., Leuenberger, M., Uglietti, C., Dolman, A. J., Ciais, P., Heimann, M., and Tans, P. P.: Seven Years of Recent European Net Terrestrial Carbon Dioxide Exchange Constrained by Atmospheric Observations, Glob. Change Biol., 16, 1317-1337. doi:10.1111/j.13652486.2009.02078.x, 2010.

Peylin, P., Rayner, P. J., Bousquet, P., Carouge, C., Hourdin, F., Heinrich, P., Ciais, P., and AEROCARB contributors: Daily $\mathrm{CO}_{2}$ flux estimates over Europe from continuous atmospheric measurements: 1, inverse methodology, Atmos. Chem. Phys., 5, 3173-3186, doi:10.5194/acp-5-3173-2005, 2005.

Peylin, P., Houweling, S., Krol, M. C., Karstens, U., Rödenbeck, C., Geels, C., Vermeulen, A., Badawy, B., Aulagnier, C., Pregger, T., Delage, F., Pieterse, G., Ciais, P., and Heimann, M.: Importance of fossil fuel emission uncertainties over Europe for $\mathrm{CO}_{2}$ modeling: model intercomparison, Atmos. Chem. Phys., 11, 66076622, doi:10.5194/acp-11-6607-2011, 2011.

Piao, S. L., Fang, J. Y., Ciais, P. Peylin, P., Huang, Y., Sitch, S., and Wang, T.: The carbon balance of terrestrial ecosystems in China, Nature, 458, 1009-1014, 2009.

Randerson, J. T., Thompson, M. V., Conway, T. J., Fung, I. Y., and Field, C. B.: The contribution of terrestrial sources and sinks to trends in the seasonal cycle of atmospheric carbon dioxide, Global Biogeochem. Cy., 11, 535-560, 1997.

Raupach, M. R., Rayner, P. J., Barrett, D. J., Defries, R. S., Heimann, M., Ojima, D. S., Quegan, S., and Schmullius, C. C.: Model-data synthesis in terrestrial carbon observation: methods, data requirements and data uncertainty specifications, Glob. Change Biol., 11, 378-397, doi:10.1111/j.13652486.2005.00917.x, 2005.

Rayner, P. J., Enting, I. G., Francey, R. J., and Langenfelds, R.: Reconstructing the recent carbon cycle from atmospheric $\mathrm{CO}_{2}$, $\delta^{13} \mathrm{C}$ and $\mathrm{O}_{2} / \mathrm{N}_{2}$ observations, Tellus B, 51, 213-232, 1999.

Rayner, P. J., Scholze, M., Knorr, W., Kaminski, T., Giering, R., and Widmann, H. : Two decades of terrestrial carbon fluxes from a carbon cycle data assimilation system (CC-DAS), Global Biogeochem. Cy., 19, GB2026, doi:10.1029/2004GB002254, 2005. 
Rayner, P. J., Law, R. M., Allison, C. E., Francey, R. J., Trudinger, C. M., and Pickett-Heaps, C.: Interannual variability of the global carbon cycle (1992-2005) inferred by inversion of atmospheric $\mathrm{CO}_{2}$ and $d^{13} \mathrm{CO}_{2}$ measurements, Global Biogeochem. Cy., 22, GB3008, doi:10.1029/2007GB003068, 2008.

Rödenbeck C., Houweling, S., Gloor, M., and Heimann, M.: Timedependent atmospheric $\mathrm{CO}_{2}$ inversions based on interannually varying tracer transport, Tellus B, 55, 488-497, 2003.

Rödenbeck, C., Estimating $\mathrm{CO}_{2}$ sources and sinks from atmospheric mixing ratio measurements using a global inversion of atmospheric transport, Technical Report 6, Max Planck Institute for Biogeochemistry, Jena, http://www.bgc-jena.mpg.de/ uploads/Publications/TechnicalReports/tech_report6.pdf, 2005.

Rodgers, C. D.: Inverse methods for atmospheric sounding: theory and practice, World Scientific, 256 pp., 2000.

Sarmiento, J. L., Gloor, M., Gruber, N., Beaulieu, C., Jacobson, A. R., Mikaloff Fletcher, S. E., Pacala, S., and Rodgers, K.: Trends and regional distributions of land and ocean carbon sinks, Biogeosciences, 7, 2351-2367, doi:10.5194/bg-7-2351-2010, 2010.

Schulze, E. D., Ciais, P., Luyssaert, S., Schrumpf, M., Janssens, I. A., Thirchittampalam, B., Theloke, J., Saurat, M., Bringezu, S., Lelieveld, J., Lohila, A., Rebmann, C., Jung, M., Bastviken, D., Abril, G., Grassi, G., Leip, A., Freibauer, A., Kutsch, W., Don, A., Nieschulze, J., Börner, A., Gash, J. H., and Dolman, A. J.: The European carbon balance. Part 4: Integration of carbon and other trace-gas fluxes, Glob. Change Biol., 1451-1469, 2010.

Sitch, S., Huntingford, C., Gedney, N., Levy, P. E., Lomas, M., Piao, S., Betts, R., Ciais, P., Cox, P., Friedlingstein, P., Jones, C. D., Prentice, I. C., and Woodward, F. I.: Evaluation of the terrestrial carbon cycle, future plant geography, and climate-carbon cycle feedbacks using 5 Dynamic Global Vegetation Models (DGVMs), Glob. Change Biol., 14 1-25, doi:10.1111/j.13652486.2008.01626.x, 2008.

Stephens, B. B., Gurney, K. R., Tans, P. P., Sweeney, C., Peters, W., Bruhwiler, L., Ciais, P., Ramonet, M., Bousquet, P., Nakazawa, T., Aoki, S., Machida, T., Inoue, G., Vinnichenko, N., Lloyd, J., Jordan, A., Heimann, M., Shibistova, O., Langenfelds, R. L., Steele, L. P., Francey, R. J., and Denning, A. S.: Weak Northern and Strong Tropical Land Carbon Uptake from Vertical Profiles of Atmospheric $\mathrm{CO}_{2}$, Science, 316, 1732-1735, doi:10.1126/science.1137004, 2007.

Suntharalingam, P., Randerson, J., Krakauer, N., Logan, J., and Jacob, D.: Influence of reduced carbon emissions and oxidation on the distribution of atmospheric $\mathrm{CO}_{2}$ : Implications for inversion analyses, Global Biogeochem. Cy., 19, GB4003, doi:10.1029/2005GB002466, 2005.
Takahashi, T., Wanninkhof, R. H., Feely, R. A., Weiss, R. F., Chipman, D. W., Bates, N., Olafsson, J., Sabine, C., and Sutherland, S. C.: Net sea-air $\mathrm{CO}_{2}$ flux over the global oceans: An improved estimate based on the sea air $\mathrm{pCO}_{2}$ difference, in: Extended $\mathrm{Ab}$ stracts of the 2nd International $\mathrm{CO}_{2}$ in the Oceans Symposium, Tsukuba, Japan, 18-22 January 1999, edited by: Y. Nojiri, 9-15, Natl. Inst. for Environ. Stud., Tsukuba, Japan, 1999.

Takahashi, T., Sutherland, S. C., Sweeney, C., Poisson, A., Metzl, N., Tillbrook, B., Bates, N., Wanninkhof, R., Feely, R. A., Sabine, C., Olafsson, J., and Nojiri, Y.: Global sea-air $\mathrm{CO}_{2}$ flux based on climatological surface ocean $p \mathrm{CO}_{2}$, and seasonal biological and temperature effects, Deep-Sea Res. Pt. II, 49, 16011622, 2002.

Takahashi, T., Sutherland, S. C., Wanninkhof, R., Sweeney, C., Feely, R. A., Chipman, D. W., Hales, B., Friederich, G., Chavez, F., Sabine, C., Watson, A., Bakker, D. C. E., Schuster, U., Metzl, N., Yoshikawa-Inoue, H., Ishii, M. Midorikawa, T., Nojiri, Y., Kortzinger, A., Steinhoff, T., Hoppema, M., Olafsson, J., Arnarson, T. S., Tillbrook, B., Johannessen, T., Olsen, A., Bellerby, R., Wong, C. S., Delille, B., Bates, N. R., and de Baar, H. J. W.: Climatological mean and decadal change in surface ocean $p \mathrm{CO}_{2}$ and net sea-air $\mathrm{CO}_{2}$ flux over the global oceans. Deep-Sea Res. Pt. II, 56, 554-577, doi:10.1016/j.dsr2.2008.12.009, 2009.

Tans, P. P., Conway, T. J., and Nakazawa, T.: Latitudinal Distribution of the Sources and Sinks of Atmospheric Carbon Dioxide Derived from Surface Observations and an Atmospheric Transport Model, J. Geophys. Res., 94, 5151-5172, 1989.

Tarantola A.: Inverse Problem Theory: Methods for Data Fitting and Model Parameter Estimation, Elsevier, Amsterdam, 1987.

Tarantola, A.: Inverse Problem Theory and Methods for Model Parameter Estimation, Society for Industrial and Applied Mathematics, Philadelphia, USA, 343 pp., 2005.

van der Werf, G. R., Randerson, J. T., Giglio, L., Collatz, G. J., Kasibhatla, P. S., and Arellano Jr., A. F.: Interannual variability in global biomass burning emissions from 1997 to 2004, Atmos. Chem. Phys., 6, 3423-3441, doi:10.5194/acp-6-3423-2006, 2006.

Wanninkhof, R., Park, G.-H., Takahashi, T., Sweeney, C., Feely, R., Nojiri, Y., Gruber, N., Doney, S. C., McKinley, G. A., Lenton, A., Le Quéré, C., Heinze, C., Schwinger, J., Graven, H., and Khatiwala, S.: Global ocean carbon uptake: magnitude, variability and trends, Biogeosciences, 10, 1983-2000, doi:10.5194/bg10-1983-2013, 2013.

Yuen, C. W., Higuchi, K., and Transcom-3 modellers: Impact of Fraserdale $\mathrm{CO}_{2}$ observations on annual flux inversion of the North American boreal region, Tellus B, 57, 203-209, 2005. 